\title{
Universiteit
}

Leiden

The Netherlands

\section{Lili Wu Chinese}

Chen, Y.; Shi, M.

\section{Citation}

Chen, Y., \& Shi, M. (2020). Lili Wu Chinese. Journal Of The International Phonetic Association, 1-23. doi:10.1017/S0025100320000092

Version: $\quad$ Publisher's Version

License: $\quad$ Licensed under Article 25fa Copyright Act/Law (Amendment Taverne)

Downloaded from: $\quad$ https://hdl.handle.net/1887/3201108

Note: To cite this publication please use the final published version (if applicable). 


\title{
Lili Wu Chinese
}

\author{
Menghui Shi \\ Leiden University Centre for Linguistics (LUCL) \\ smhfudan@163.com
}

Yiya Chen 10

Leiden University Centre for Linguistics (LUCL) \& Leiden Institute for Brain and Cognition (LIBC)

yiva.chen@hum.leidenuniv.nl

Lili Wu Chinese (黎里话) is a Wu dialect (吴语; ISO 639-3; code: wuu) spoken by approximately 38,000 people who reside in the town of Lili (黎里镇), one of the ten major towns in the Wujiang district (吴江区). The Wujiang district belongs to the prefectural-level municipality of Suzhou city (苏州市) in Jiangsu province (江苏省), the People's Republic of China. It is located at the juncture area of the city of Shanghai (上海市), the city of Suzhou, and the city of Jiaxing (嘉兴市), as shown in Figure 1.

Lili Wu Chinese is commonly considered to belong to the Suhujia dialect cluster (苏沪嘉小片), which in turn is classified as a member of the Tai Lake subgroup (太湖片) of the Northern Wu dialect group, a Sinitic branch within the Sino-Tibetan family (Wurm et al. 1987: B-9). The dialect is famous for the so-called aspiration-induced tonal split phenomenon, which refers to the lowering of f0 contours after voiceless aspirated obstruents in

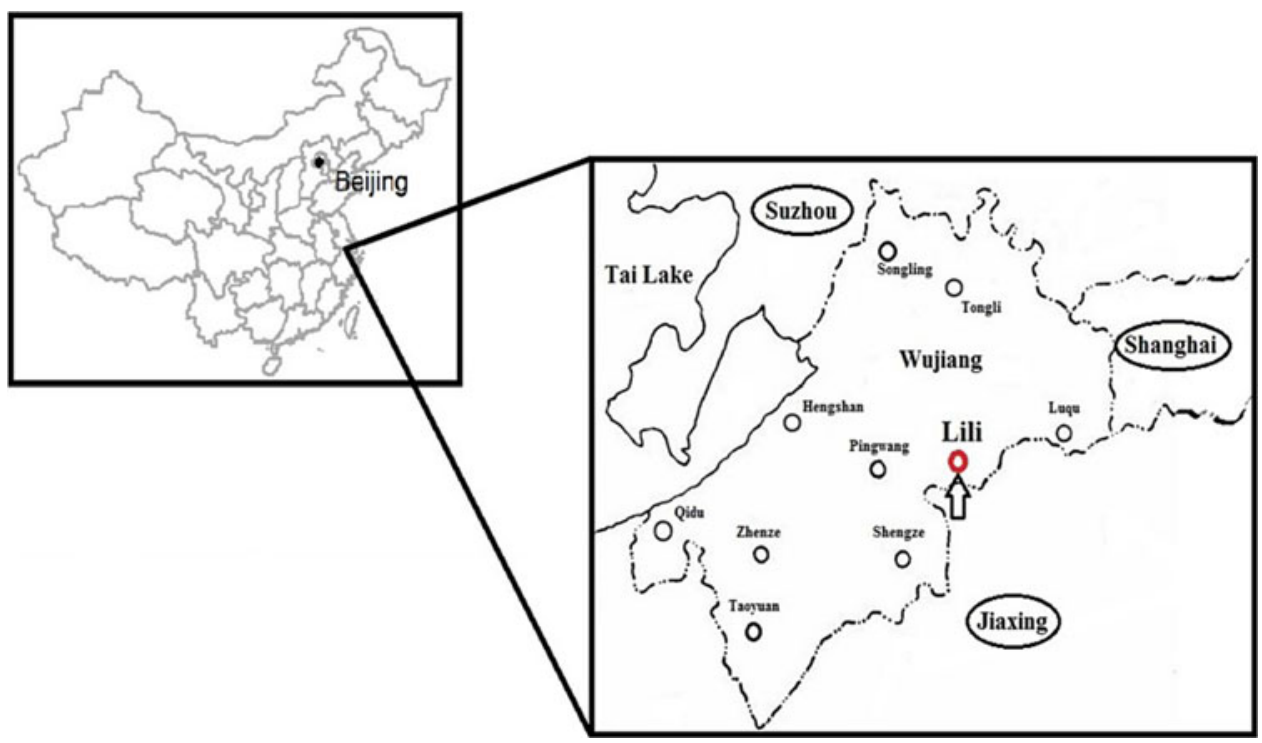

Figure 1 (Colour online) Map of the Wujiang dialects (modified based on the map in Ye 1983). 
certain tonal contexts. ${ }^{1}$ Lili Wu Chinese has therefore attracted much attention over the last six decades, which led to a handful of descriptions not only on the dialect but also on its closely-related dialects in the Wujiang area which appear to have similar aspiration-induced tonal splits. Perhaps because of this salient tonal-split feature in the dialect, much less attention has been paid to the segmental properties of Lili Wu Chinese in the existing literature. This description aims to bring together existing descriptions of Lili Wu Chinese in an accessible form, as well as to propose a number of methodological/analytical innovations and new perspectives with regard to not only lexical tones but also segmental features. Specifically, they are: (i) an instrumental analysis of the lexical tones and a reanalysis of the co-occurrence pattern between lexical tone and onset; (ii) acoustic realizations of voiceless vs. voiced fricatives; (iii) detailed phonetic analyses of two high front vowels $/ \mathrm{i} /$ and $/ \mathrm{i} /$; and (iv) the addition of two syllabic approximants / $/ \mathbf{I} /$ and $/ \mathbf{d} /$ in the sound system of Lili Wu Chinese.

The description is mainly accompanied by recordings of a sixty-eight-year-old male native speaker, who was born in 1948 and raised in Lili town. All acoustic data we present in this description were elicited from this consultant. Our consultant spent most of his life living in Lili and speaking Lili Wu Chinese, except for the three years attending a college in a nearby city. According to his self-report, he can speak (accented) Standard Chinese and limited Shanghainese when the situation requires him to do so, but he speaks only Lili Wu Chinese at home. All video recordings were elicited from another male native speaker, who was born in 1947 and raised in Lili town as well.

\begin{tabular}{|c|c|c|c|c|}
\hline \multicolumn{5}{|c|}{ Lexical tones and aspiration-induced tonal split } \\
\hline $\mathrm{T} 1$ & high-level & $/ \operatorname{tun}^{1 /}$ & 东 & 'east' \\
\hline $\mathrm{T} 2$ & low-rising & $/ \mathrm{dun}^{2} /$ & 铜 & 'copper' \\
\hline $\mathrm{T} 3$ & high-falling & $/ \mathrm{tun}^{3} /$ & 懂 & 'to understand' \\
\hline $\mathrm{T} 4$ & low-level & $/ \mathrm{dun}{ }^{4} /$ & 动 & 'action' \\
\hline $\mathrm{T} 5$ & high-dipping & $/$ tun $^{5} /$ & 冻 & 'to freeze' \\
\hline T6 & low-dipping & $/ \mathrm{dun}^{6} /$ & 洞 & 'cave' \\
\hline $\mathrm{T} 7$ & short-high-level & $\mid \operatorname{tuP}^{7} /$ & 督 & 'supervision' \\
\hline $\mathrm{T} 8$ & short-low-level & $/ \mathrm{d} u 1^{8} /$ & 读 & 'to read' \\
\hline
\end{tabular}

There are eight lexical tones in Lili Wu Chinese. Plotted in Figure 2 are the f0 contours of the example morphemes, labelled as T1 to T8, respectively. Generally speaking, lexical tones marked as odd numbers start within a higher f0 range (above $160 \mathrm{~Hz}$, high-register hereafter), while those marked as even numbers start within a lower range (under $160 \mathrm{~Hz}$, lowregister hereafter). T1 (black solid) has a level f0 contour within the high-register (high-level) while T2 (dark grey solid) is a low-register rising tone (low-rising). T3 (black round dot)

\footnotetext{
${ }^{1}$ In the literature, the same phenomenon has been referred to as Songqifendiao [送气分调, lit.: 'aspiration divides tones'] (e.g. Ho 1989), Qiliufendiao [气流分调, lit.: 'airflow divides tones'] (Yue Xu 2006), or Ciqingfendiao [次清分调, lit.: 'secondary voiceless divides tones'] (Zhu \& Yue Xu 2009). The English appellations include 'aspiration-conditioned tone-lowering' (Sagart 1981), 'tone-split by aspiration' (Ho 1989), 'aspirated tones' (Shen 1994), 'tonal split based on the aspiration' (F. Shi 1998), and 'tonal split following voiceless aspirated stop onsets' (Chen 2011).
} 
starts within the high-register and falls (high-falling). T4 (dark grey round dot) is a lowregister level tone (low-level). T5 (black square dot) has a convex contour which starts at the high-register, falls and ends with a slight rise (high-dipping). T6 (dark grey square dot) is realized with a similar f0 contour to that of T5 but starts at the low-register (low-dipping). Both T7 (black dash-dotted) and T8 (dark grey dash-dotted) are associated with syllables that have a much shorter duration than the other tone-bearing syllables. T7 starts within the high-register and despite the slight falling contour, sounds like a high-register level tone (short-high-level). T8 is a low-register level tone (short-low-level).

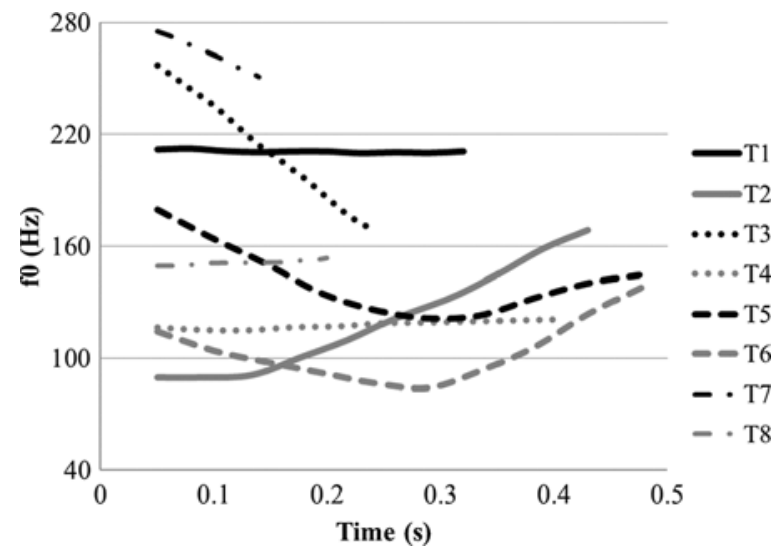

Figure 2 FO contours of the lexical tones of the example words.

These eight lexical tones exhibit interesting co-occurrence patterns with both the onset and coda. Lili $\mathrm{Wu}$ Chinese features the three-way laryngeal contrast in obstruents, known as voiceless unaspirated, voiceless aspirated and voiced, respectively. (See the section on consonants below for more details.) Syllables with voiceless unaspirated onsets only allow high-register tones (T1, T3, T5, and T7); while voiced onsets co-occur with low-register tones (T2, T4, T6, and T8). T1 to T6 only co-occur with open syllables or syllables with a nasal coda (舒声) and are therefore also known as smooth/non-checked tones (developing from the Ping [平, level], Shang [上, rising], and $Q u$ [去, departing] tonal categories of Middle Chinese), while the T7 and T8 only co-occur with closed syllables with a glottal coda/R/ (促声) and are known as abrupt/checked tones (developing from the $R u$ [入, entering] tonal category of Middle Chinese).

In the vast majority of Northern Wu dialects such as Shanghainese (Chen \& Gussenhoven 2015), both voiceless unaspirated and aspirated onsets condition high-register tones, leaving voiced onsets to co-occur with low-register tones. What makes Lili Wu Chinese interesting is the effect of obstruent aspiration on lexical tonal realization, as exemplified by $/ \mathrm{t}^{\mathrm{h}} \mathrm{uj} /$

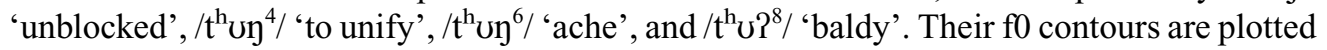
in Figure 3 (labelled as T1-A, T3-A, T5-A, and T7-A where A indicates voiceless aspirated onsets), in comparison to the f0 contours of the presumably same lexical tones realized after voiceless unaspirated onsets (indicated with U). Except for T1 (i.e. T1-U vs. T1-A), we see a clear f0-lowering effect in syllables with voiceless aspirated onsets. This lowering effect, as if a split of the same tone into two as a function of voiceless unaspirated vs. aspirated onsets, is known as aspiration-induced tonal split. 


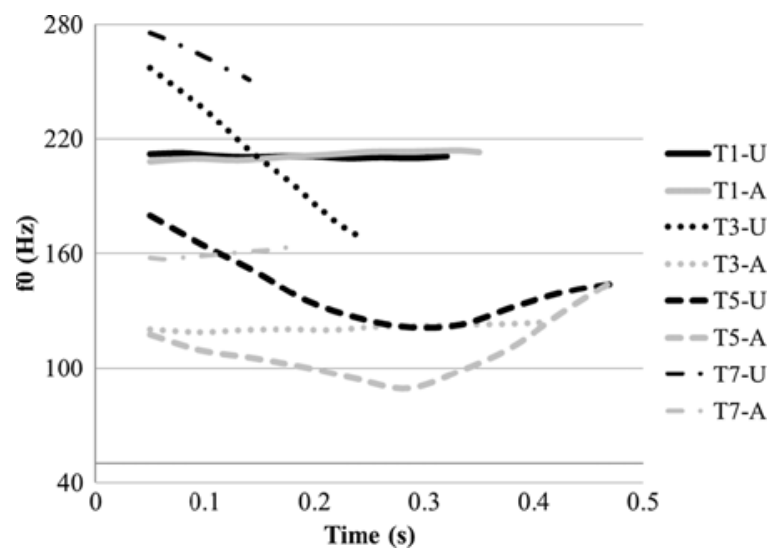

Figure 3 FO contours of the lexical tones of the words with voiceless unaspirated onsets (U, black) and those with voiceless aspirated onsets (A, light grey).

Perhaps due to this prominent phenomenon, the tonal inventory in Lili Wu Chinese has been a point of debates in recent decades. To our knowledge, there are at least eleven descriptive works focusing on this aspiration-induced tonal-split phenomenon in Lili Wu Chinese (Chao 1928: 82; Ye 1983; Zhang \& Liu 1983; F. Shi 1992; Qian 1992: 48; Shen 1994; P. Wang 2008, 2010: 26-27; Z. Xu 2009: 55; Hirayama 2010; Yanhong Xu 2013: 32). Researchers differ greatly in their treatment/interpretation of the tonal-split phenomenon. The main debate lies in the question of whether the fo contours of lexical tones after aspirated onsets have been merged with those after voiced onsets or emerged as distinct tonal categories independent of the existing eight tonal categories. It is important to note that previous studies typically explore this phenomenon based on impressionistic descriptions (e.g. Chao 1928: 8-10), or with data from a very limited number of speakers (e.g. F. Shi 1992 for one male and one female speakers; Shen 1994 for two young speakers).

M. Shi, Chen \& Mous (2016), with data from twenty native speakers (eight males and 12 females with mean age of 67 years and standard deviation of six years), show comparable f0 contours after voiceless aspirated (T1-A) and voiceless unaspirated (T1-U) onsets, both of which are realized within the high register, as shown in Figure 4(a). However, the f0 contours after voiceless aspirated onsets can also pattern more like those after voiced onsets, resulting in the merger of the $\mathrm{f} 0$ contours of T3-A and T4, T5-A and T6, T7-A and T8, respectively, as plotted in Figure 4(b-c). F0 contours after aspirated onsets show a trend of slightly higher f0. Suggested by the statistical results (growth curve analysis, GCA) in M. Shi et al. (2016), there is no significant difference between fo contours after voiceless aspirated and voiced onsets for each pair.

In summary, the lexical tonal system of Lili Wu Chinese includes two level tones (high-level T1 and low-level T4), one falling tone (high-falling T3), one rising (low-rising T2) and two dipping tones (high-dipping T5 and low-dipping T6). For short syllables with a glottal coda, two level tones are identified (short-high-level T7 and short-low-level T8). The numerical representations of the eight lexical tones and their co-occurrence patterns with onsets are provided in Table 1 . Here, we adopted the tonal transcription system developed by Chao (1930) where 5 indicates the highest end of a speaker's pitch range into levels and 1 the lowest.

T1 can co-occur with both voiceless onsets (i.e. unaspirated and aspirated). T3, T5, and $\mathrm{T} 7$, on the other hand, can only co-occur with voiceless unaspirated onsets. The three lowregister tones (T4, T6, and T8) are licensed by both voiceless aspirated and voiced onsets, while $\mathrm{T} 2$ is only allowed after voiced onsets. It is important to note that the co-occurrence pattern (i.e. voiceless onsets co-occurring with high-register tones, while voiced onsets with 
Table 1 Numerical representations of the lexical tones in Lili Wu Chinese. A single number refers to cases where the tone-carrying syllables have short duration and only co-occur with the glottal coda / $/$.

\begin{tabular}{lllll}
\hline Voiceless unaspirated (U) & T1 high-level 44 & T3 high-falling 53 & T5 high-dipping 423 & T7 short-high-level 5 \\
Voiced (D) & T2 low-rising 13 & T4 low-level 22 & T6 low-dipping 213 & T8 short-low-level 3 \\
Voiceless aspirated (A) & T1 high-level 44 & T4 low-level 22 & T6 low-dipping 213 & T8 short-low-level 3 \\
\hline
\end{tabular}

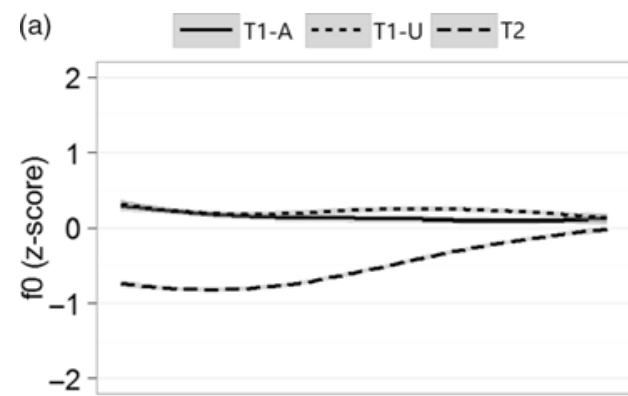

Normalized Time

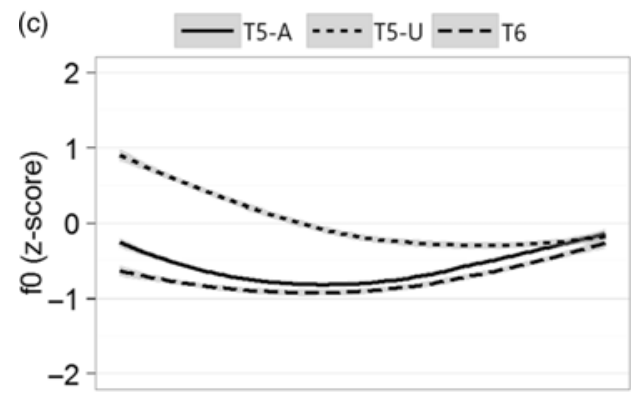

Normalized Time

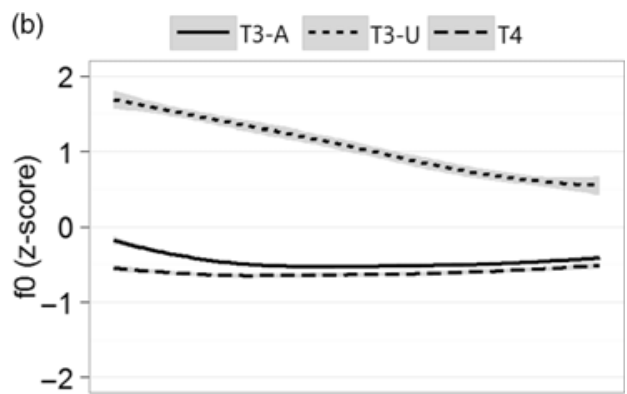

Normalized Time

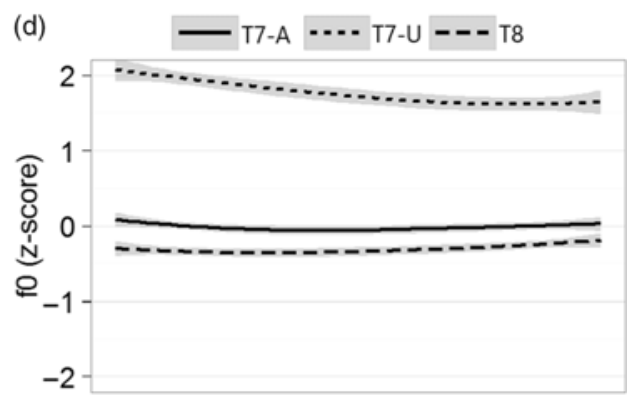

Normalized Time

Figure 4 Normalized average fo contours of the lexical tones based on data from twenty native speakers (eight males and 12 females with mean age of 67 years and standard deviation of six years). Each participant read a minimal set of 36 real monosyllabic words with three laryngeal-alveolar contrasts (voiceless unaspirated, voiceless aspirated, and voiced) combined with three vowels (low, middle, and high). The grey areas indicate $( \pm 1)$ one standard error of the mean. Adopted from M. Shi et al. (2016).

low-register ones), which is commonly observed in most Northern $\mathrm{Wu}$ dialects, falls apart in Lili Wu Chinese where voiceless aspirated onsets can co-occur with low-register tones.

In addition, it is worth noting that in Lili Wu Chinese, sonorants (i.e. nasals and liquids) mainly co-occur with low-register tones and share the same tonal pattern with voiced plosives. A set of words initialed with nasals can also co-occur with high-register tones, such as $/ \mathrm{mu}^{3} /\left[\mathrm{mov}^{3}\right]$ 'bound morpheme for the literary address of mother'. ${ }^{2}$ With respect to fricatives, since there is only a two-way laryngeal distinction (i.e. voiceless vs. voiced), voiceless fricatives co-occur with high-register tones while their voiced counterparts with low-register ones.

${ }^{2}$ In Northern Wu Chinese, there is a group of shared words with nasal initials 妈/母/美/蛮/因, 'bound morpheme for mother/bound morpheme for the literary address of mother/beautiful/very/little darling') that can co-occur with high-register tones. Such a co-occurrence is argued to be relevant to the affective function of high tones (Zhu 2004a). 


\section{Consonants}

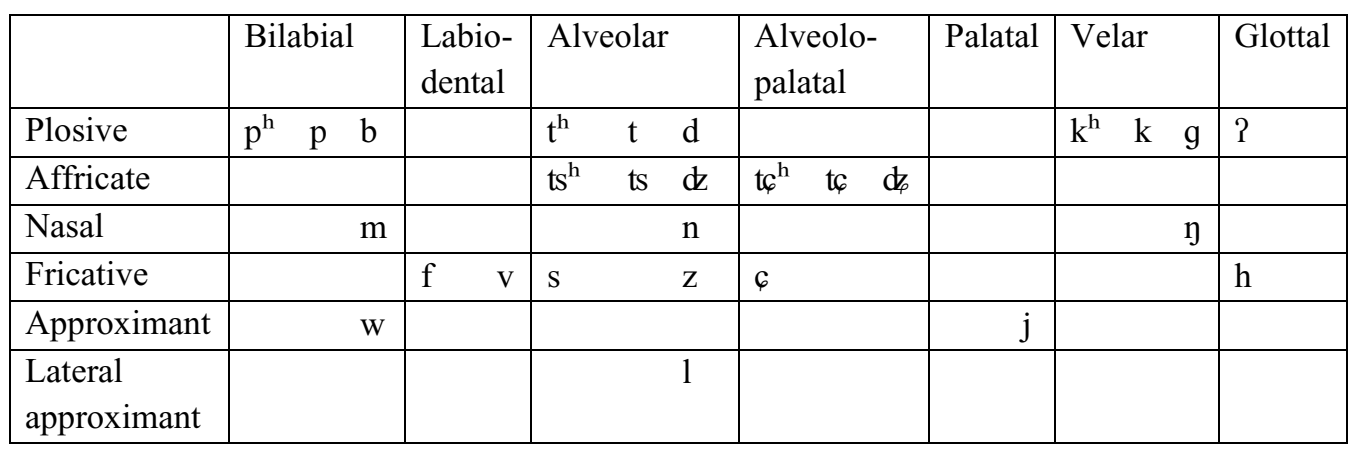

$\mathrm{p}^{\mathrm{h}} \quad \mathrm{p}^{\mathrm{h}} \varepsilon^{1}$ 攀 ‘to climb’ $\quad \mathrm{t}^{\mathrm{h}} \quad \mathrm{t}^{\mathrm{h}} \varepsilon^{1} \quad$ 瘫 ‘paralysis’ $\mid \mathrm{k}^{\mathrm{h}} \quad \mathrm{k}^{\mathrm{h}} \varepsilon^{1} \quad$ 开 'to open'

\begin{tabular}{llllll|lll}
$\mathrm{p}$ & $\mathrm{p} \varepsilon^{1}$ & 班 'class' & $\mathrm{t}$ & $\mathrm{t} \varepsilon^{1}$ & 单 'single' & $\mathrm{k}$ & $\mathrm{k} \varepsilon^{1}$ & 该 'ought to'
\end{tabular}

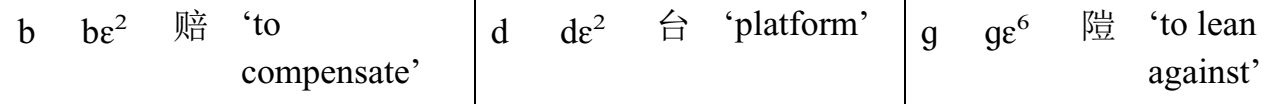

$\mathrm{f} \quad \mathrm{f}^{1}$ 翻 'to turn over' $\mathrm{ts}^{\mathrm{h}} \mathrm{ts}^{\mathrm{h}} \varepsilon^{1}$ 猜 'to guess' $\mathrm{P} \quad \mathrm{k} \Lambda \mathrm{P}^{7}$ 割 'to cut'

$\mathrm{v} \quad \mathrm{v} \varepsilon^{2}$ 烦 'to bother' $\quad$ ts $\mathrm{ts}^{1}$ 灾 'disaster'

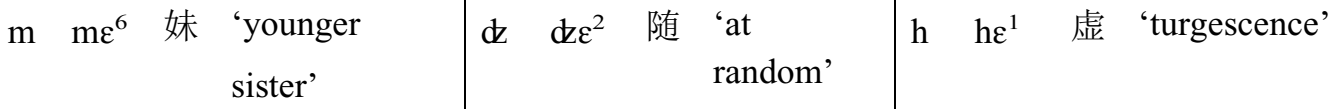

$\mathrm{w} \mathrm{w}^{2}$ 还 'to return' tc $\mathrm{tc}^{\mathrm{h}} \mathrm{tc}_{+}^{\mathrm{h}}{ }^{1}$ 欺 'to

deceive'

t6 tci $_{+}^{1}$ 鸡 'chicken'

$\mathrm{d}_{\mathrm{e}} \quad \mathrm{d}_{+} \mathrm{i}^{2}$ 奇 'strange'

$\mathrm{n} n \varepsilon^{2}$ 难 'difficult'

$\mathrm{s} \quad \mathrm{s} \varepsilon^{1} \quad$ 三 'three'

$\mathrm{z} \varepsilon^{2}$ 悗 'greedy'

$6 \quad \operatorname{ci}_{+}^{1}$ 稀 'rare'

j jọo ${ }^{1}$ 优 'superior'

$1 \quad 1 \varepsilon^{2}$ 蓝 'blue' 
Lili Wu Chinese has 28 consonants. Corresponding key words/bound morphemes are provided below the consonant chart. Lili Wu Chinese features the three-way laryngeal contrast in obstruents, known as voiceless unaspirated, voiceless aspirated and voiced, respectively (Chao 1967). This three-way contrast is a prominent feature of the Northern Wu dialects. The three-way laryngeal contrast, however, has different phonetic manifestations in the initial vs. medial positions within a word. Generally speaking, in the initial position, these obstruents vary in their phonation from clearly modal (voiceless unaspirated), aspirated with breathiness (voiceless aspirated), to breathy (voiced) (M. Shi et al. 2016). In the medial position, voiced obstruents are realized with noticeable voicing throughout the closure, leading to a threeway laryngeal distinction in terms of voice onset time (VOT). In Shanghai Wu Chinese, a Northern $\mathrm{Wu}$ dialect closely related to Lili $\mathrm{Wu}$, there are other phonetic properties to signal the three-way laryngeal contrast in both initial and medial positions (e.g. Shen, Wooters \& W S.-Y. Wang 1987 on closure duration; Ren 1992: 95-111 on transillumination data; Gao 2015: 199-207 on motion-capture-system data; see also a review in Chen 2011). Impressionistically speaking, Lili Wu behaves similarly to Shanghainese. Needless to say, more research is needed to examine if these properties also function in Lili Wu Chinese.

Fricatives have the voiceless vs. voiced two-way laryngeal contrast. Similar to the plosives and affricates, in the initial position, their phonatory states vary from clearly modal in the voiceless ones to slightly breathy in the voiced ones. In medial position, the voiced category is realized as vigorous voicing, leading to a two-way contrast in terms of VOT. It is worth noting that the fricative voicing contrast is also signaled via their durational differences, similar to what have been reported for voicing contrast in English fricatives (Cole \& Cooper 1975), as shown in the following pairs: /f/ (/ful/ 'husband') vs. /v/ (/ $\mathrm{vu}^{2} /$ 'support somebody with one's hand'); /s/ (/se $1 /$ 'three') vs. $/ \mathrm{z} /\left(/ \mathrm{z \varepsilon}^{2} /\right.$ 'greedy'). Figure 5 illustrates the acoustic realization of $/ \mathrm{f} / \mathrm{in} / \mathrm{fu}^{1} /(6 \mathrm{a})$ and $/ \mathrm{v} / \mathrm{in} / \mathrm{vu}^{2} /(6 \mathrm{~b})$. Although neither is realized with regular vocal pulses (i.e. phonetically voiceless), the fricative duration of $/ \mathrm{f} /(131 \mathrm{~ms} ; 29 \%$ of the total duration) is almost 2.4 times longer than that of $/ \mathrm{v} /(56 \mathrm{~ms} ; 12 \%$ of the total duration).

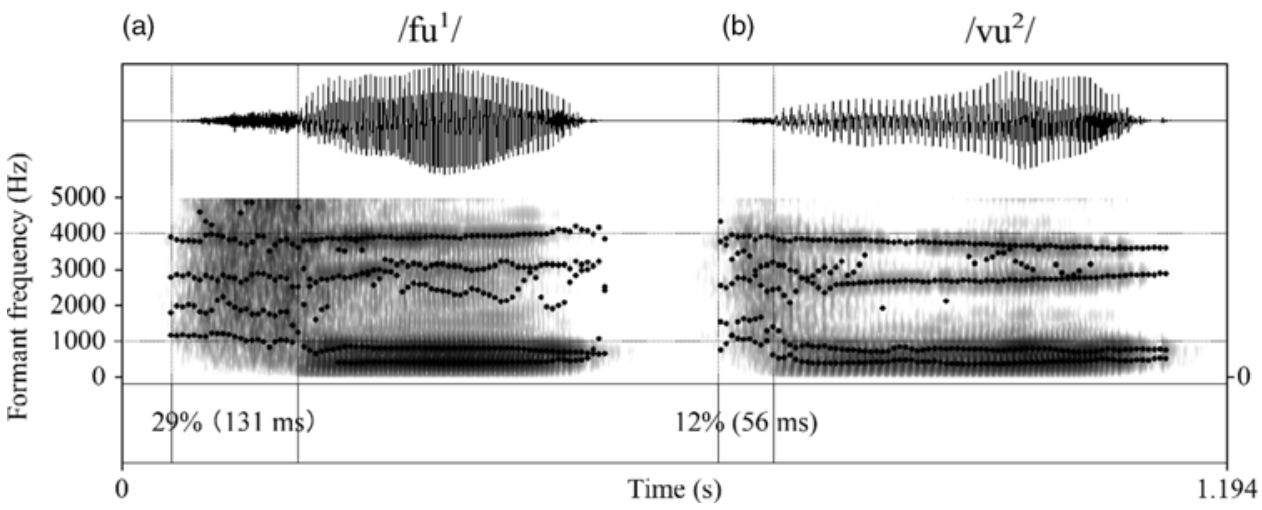

Figure 5 Waveforms and spectrograms of (a) / $\mathrm{fu}^{1 /}$ 'husband' and (b) / $\mathrm{vu}^{2} /$ 'support somebody with one's hand'. Within a syllable, the percentage of the frication duration with absolute values (ms) between parentheses is indicated.

To further confirm these observations, we elicited ten minimal pairs for each minimal set of voicing contrast. All stimuli were lexemes of relatively high familiarity, as confirmed by our consultant. Both the absolute duration of the frication and the percentage of the frication duration over the whole syllable duration were calculated. The fricative duration was measured from the onset of clear frication noise to the first periodic cycle of the vowel. Results in Table 2 show that the percentage of the frication duration of voiceless onsets is significantly greater than that of their voiced counterparts, confirmed by the results of the independent samples $t$-tests (one-tailed) for each pair. 
Table 2 The average percentage of the frication duration and the independent samples $t$-test results for each pair of voiceless vs. voiced onsets. Parentheses indicate absolute values of the average duration (mean) and the standard deviation (sd).

\begin{tabular}{lll}
\hline Voiceless vs. voiced & Frication duration & $t$-test \\
\hline $\mathrm{f}$ vs. v & $27 \%($ mean $=124 \mathrm{~ms}, s d=7 \mathrm{~ms})$ vs. $12 \%($ mean $=59 \mathrm{~ms}, s d=4 \mathrm{~ms})$ & $t(18)=10.79, p<.001$ \\
s vs. z & $36 \%($ mean $=149 \mathrm{~ms}, s d=8 \mathrm{~ms})$ vs. $28 \%($ mean $=117 \mathrm{~ms}, s d=6 \mathrm{~ms})$ & $t(18)=2.74, p<.01$ \\
\hline
\end{tabular}

Last but not least, /dz/ and /z/ are sometimes in free variation for the same lexical item, as exemplified in 'groceries' $\left(/ \mathrm{da}^{8} \mathrm{hu}^{5} / \mathrm{vs}\right.$. $\left./ \mathrm{za}^{8} \mathrm{hu}^{5} /\right)$. This finding may imply that in Lili $\mathrm{Wu}$ Chinese, the affricate /dz/ and fricative / $\mathrm{z} /$ are undergoing merger at the lexical level. The glottal plosive / $/$ / only appears in coda position as a phoneme and co-occurs with short syllables as in $/ \mathrm{pa}^{7} /$ 'hundred'. Phonetically speaking, the [?] segment can be observed at the beginning of onsetless syllables with the high-register tones (i.e. T1, T3, T5, and T7) (see the section below for further details on onsetless syllables).

\section{Sonorants}

/n 1/ are typical laminal alveolar. The alveolar nasal /n/ is palatalized before high front segments (i.e. $/ \mathrm{i} \mathrm{i} \mathrm{y} \mathrm{j/),} \mathrm{as} \mathrm{in} / \mathrm{ni}^{2} /\left[\mathrm{ni}^{2}\right]$ ' 'year' and $/ \mathrm{nje}^{6} /\left[\mathrm{nj}^{6}\right]^{6}$ 'to read'. Labial and velar nasals can form syllable nuclei as in $/ \mathfrak{j}^{4} /$ 'five' and $/ \mathrm{m}^{4} /$ 'parcel of land'. These two syllabic nasals can be found in many Southern Chinese dialects (i.e. Wu, Min, Hakka, Xiang, and Yue) but are relatively rare in dialects belonging to the Mandarin family (Shen 2006). In addition, /y/ occurs as a nasal coda as well, but its acoustic realization varies according to the preceding vowel. After a front vowel, the nasal coda acquires the anterior feature and sounds like [n] (as in $/ \mathrm{ZIn}^{2} /\left[\mathrm{ZIn}^{2}\right]$ 'to look for' and /t $\mathrm{YYy}^{1} /\left[\mathrm{tcYn}^{1}\right]$ 'army'), as in contrast to a non-front vowel (as in $/ \mathrm{dzoy}^{1 /}$ 'deity' and $/ \mathrm{duy}^{2} /$ 'copper'). Following the treatment of Chen \& Gussenhoven (2015) for Shanghainese, we posit an underlying / $\mathbf{y}$ in coda position.

There are two glides $/ \mathrm{j} /$ and /w/ in Lili Wu Chinese. Glides are typically defined as vowellike segments that function as consonants and belong to the approximant class (Ladefoged \& Maddieson 1996: 322). In Lili Wu Chinese, /j/ and /w/ differ from the corresponding vowels (i.e. $/ \mathrm{i} /$ and $/ \mathrm{u} /$ ) in that both tend to be produced with a narrower constriction of the vocal tract indicated via lower F1 values. Following Maddieson \& Emmorey (1985), we compared mean $\mathrm{F} 1$ of the beginning interval (i.e. $50 \mathrm{~ms})$ of $/ \mathrm{j} /\left(/ \mathrm{j}_{\mathrm{O}} \mathrm{o}^{1 /}\right.$ ' surname, Ou') with $/ \mathrm{i} /\left(/ \mathrm{i}^{1} /\right.$ 'smoke') and $/ \mathrm{w} /\left(/ \mathrm{w}^{2} /\right.$ 'to return') with $/ \mathrm{u} /\left(/ \mathrm{u}^{1} /\right.$ 'crow'), respectively. Results showed that the F1 values of $/ \mathrm{j} /(265 \mathrm{~Hz})$ and $/ \mathrm{w} /(314 \mathrm{~Hz})$ are lower than the corresponding vowels $(/ \mathrm{i} /: 271 \mathrm{~Hz}$; $/ \mathrm{u} /$ : $354 \mathrm{~Hz}$ ). Existing descriptions of Lili Wu Chinese such as P. Wang (2010: 26) have typically posited high vowels $/ \mathrm{i} \mathrm{u} / \mathrm{instead}$ of glides $/ \mathrm{j} \mathrm{w} /$ in words like $/ \mathrm{j}$ o o $/$ and $/ \mathrm{we}^{2} /\left(/ \mathrm{iau}^{1} / \mathrm{and} / \mathrm{uE}^{2} /\right.$ in P. Wang 2010: 26, respectively), ${ }^{3}$ despite the consensus among sinologists that they are glides. We have adopted the approximants $/ \mathrm{j} \mathrm{w} /$ to transcribe the sounds. Note that before rounded vowels $/ \mathrm{o} /$ and $/ \varnothing /, / \mathrm{j} /$ is realized as $[\mathrm{\varphi}]$ as in $/ \mathrm{jo} ?^{8} /\left[\mathrm{YO}^{8}{ }^{8}\right.$ ' $b$ ath' and $/ \mathrm{jø} \varnothing^{2} /\left[\mathrm{\varphi}^{2}\right]$ 'rounded'. Because of the complementary distribution, $/ \mathrm{\Psi} /$ is treated as a context-specific (i.e. before $/ \mathrm{o} /$ and $/ \varnothing /$ ) variation of $/ \mathrm{j} /$.

A controversial issue is whether it is necessary to posit $/ \mathrm{j} /$ after an alveolo-palatal affricate or fricative onset (i.e. $/ \mathrm{tc}_{\varphi}^{\mathrm{h}}$ tc $\mathrm{d}_{\mathrm{c}} \mathrm{c} /$ ) in Wu Chinese (see a brief discussion in Chen \& Gussenhoven 2015). Historically, these alveolo-palatal onsets are commonly believed to develop from the velar or glottal onsets (i.e. $/ \mathrm{k}^{\mathrm{h}} \mathrm{k} \mathrm{g} \mathrm{h} /$ ) due to the palatalization process triggered by the following high front segments (e.g. L. Wang 1985: 394). Synchronically, there

\footnotetext{
${ }^{3}$ Sinologists frequently use /E/ to describe the phoneme between /e/ and / $/$ /, which however, does not exist in the IPA.
} 


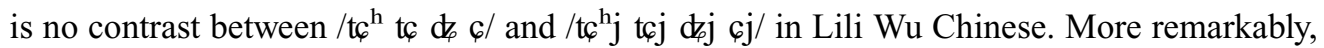
the transition from the alveolo-palatal affricate to the following vowel is rather brief. Figure 6 illustrates the different transitional characteristics among $/ \mathrm{ta}^{1} /$ ' $\mathrm{knife}$ ' (6a), where there is no glide, $/ \mathrm{tja}^{1 /}$ ' 'marten' (6b) and $/ \mathrm{tsja}^{1} /$ 'scorched' $(6 \mathrm{c})$, where there is commonly recognized presence of $/ \mathrm{j} /$, and $/ \mathrm{t} c \mathrm{a}^{1} /$ 'to converge' (6d), where we propose absence of $/ \mathrm{j} /$. Adapting the method of Chitoran (2002), we marked the beginning of the transition at the start of the sonorant part (i.e. glide or vowel) and the end of the transition as the turning point from a falling F2 to an F2 steady-state, before it falls consistently less than $20 \mathrm{~Hz}$. The F2 values were automatically measured in Praat (Boersma \& Weenink 2020) with a window length of $5 \mathrm{~ms}$. Note that we would have expected a much more stable realization of $/ \mathrm{j} /$ with longer transition from $/ \mathrm{t}_{6} /$ to $/ \mathrm{a} /$ if we assumed the presence of a glide $/ \mathrm{j} /$ following $/ \mathrm{t}_{\mathrm{c}} /$. These observations motivated us not to posit an underlying / $\mathrm{j} /$ after alveolo-palatal onsets (following the analysis of Chen \& Gussenhoven 2015 for Shanghainese). But we would like to stress the importance of further experimental studies to investigate the phonological status and phonetic realization of $/ \mathrm{j} /$ after alveolo-palatals in Lili Wu Chinese as well as other Chinese dialects.

(a) $/ \mathrm{ta}^{1} /$

(b) $/ \mathrm{tja}^{1 /}$

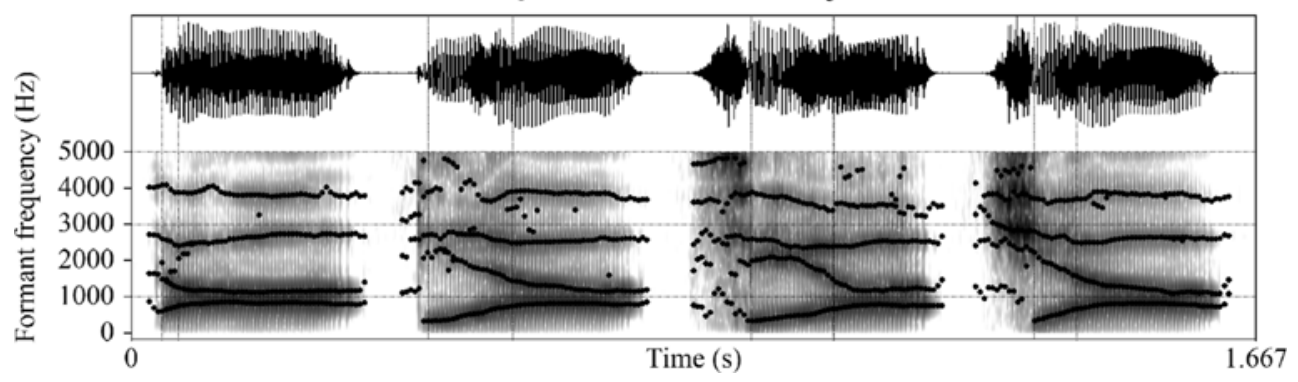

Figure 6 Waveforms and spectrograms of (a) /ta ${ }^{1 / /}$ 'knife', (b) /tja ${ }^{1 /}$ 'marten', (c) /tsja $1 /$ 'scorched', and (d) /tca $1 /$ 'to converge'. Within each syllable, the transition from the end of the preceding consonant to the time that the F2 converges toward the value of $/ \mathrm{a} /$ is indicated.

\section{Vowels}

The traditional quadrilateral vowel plot of Lili Wu monophthongs in open syllables is as follows:

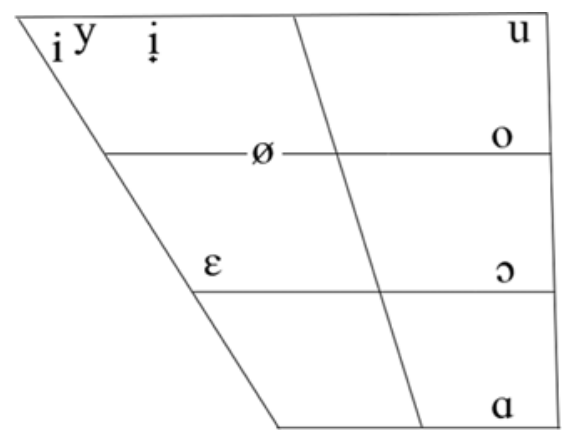


Monophthongs and diphthong in open syllables

\begin{tabular}{|c|c|c|c|c|c|c|}
\hline $\mathrm{ti}^{1}$ & 颠 & 'jolt' & $\mathrm{u}$ & $u^{1}$ & 乌 & 'crow' \\
\hline $6 y^{1}$ & 虚 & 'unreal' & $\varnothing$ & $\mathrm{k} \varnothing^{1}$ & 肝 & 'liver' \\
\hline $\mathrm{ti}_{+}^{1}$ & 低 & 'low' & o & $\mathrm{ko}^{1}$ & 瓜 & 'melon' \\
\hline $\mathrm{k} \varepsilon^{1}$ & 该 & 'ought to' & 0 & $\mathrm{zo}^{2}$ & 柴 & 'firewood' \\
\hline $\mathrm{j}_{\perp} \mathrm{o}^{1}$ & 优 & 'superior' & $a$ & $\mathrm{ka}^{1}$ & 高 & 'high' \\
\hline
\end{tabular}

Monophthongs in closed syllables and nasalized vowels

\begin{tabular}{|c|c|c|c|c|c|c|c|}
\hline I & terin ${ }^{1}$ & 金 & 'gold' & U & $\mathrm{kun}^{1}$ & 公 & 'public' \\
\hline & $\operatorname{ter} i^{7}$ & 急 & 'hurry' & & $\mathrm{kv}^{7}$ & 郭 & 'surname, Guo' \\
\hline Y & $\mathrm{tcry}^{1}$ & 军 & 'army' & $\partial$ & $k ə y^{1}$ & 跟 & 'to follow' \\
\hline$\omega$ & $\operatorname{kaP}^{7}$ & 夹 & 'to clip' & $\Lambda$ & $\mathrm{k} \Lambda \mathrm{P}^{7}$ & 革 & 'to reform' \\
\hline & $\mathrm{k} \tilde{\mathscr{X}}^{1}$ & 庚 & 'age' & $\tilde{\mathbf{a}}$ & $\mathrm{ka} \tilde{\mathbf{a}}^{1}$ & 刚 & 'just now' \\
\hline
\end{tabular}

In open syllables, there are nine monophthongs (7a) and one diphthong (7b) in Lili Wu Chinese as plotted in Figure 7. These nine monophthongs of Lili Wu Chinese (/i y i $\varepsilon \varnothing u$ o $\supset \mathrm{a} /$ ) constitute a four-way distinction (i.e. close, close-mid, open-mid, and open) in height and a two-way distinction (i.e. front and back) in backness. /i y/ contrast in roundness. In addition, there is one diphthong occurring in open syllables, with /9o/ gliding towards the back. Monophthongs in closed syllables and nasalized vowels are plotted in Figure 8, where

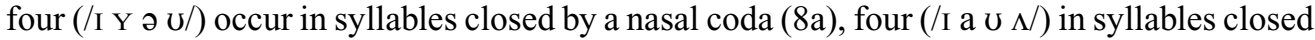
by a glottal coda $(8 \mathrm{~b})$ and two $(/ \tilde{\mathfrak{x}} \tilde{\mathrm{a}} /)$ are nasalized vowels $(8 \mathrm{c})$. Compared to the vowels in open syllables, the number of vowels in closed syllables is largely reduced and so is their acoustic vowel space. Generally speaking, vowels in closed syllables or with nasalization are more central and lower than those in open syllables. Following Chen \& Gussenhoven (2015), we adopted the same set of symbols (i.e. /I/ and / $/$ /) for monophthongs followed by a nasal coda and those by a glottal coda, although their articulations do differ. The plots of the F1-F2 values are based on accompanying sound files produced by our consultant. The mean formant value of a vowel was calculated by averaging over ten tokens (except for $/ \mathrm{u} /$ which was calculated based on five tokens).

Lili $\mathrm{Wu}$ presents an interesting case of fricative vowel, as illustrated in Figure 9, which plots the spectrograms of the minimal pair $/ \mathrm{i} / \mathrm{in} / \mathrm{ti}^{3} / \mathrm{dot}^{\prime}(9 \mathrm{a})$ and $/ \mathrm{i} / \mathrm{in} / \mathrm{ti}^{3} /$ 'bottom' $(9 \mathrm{~b})$. The F2 of /i/ $(2399 \mathrm{~Hz})$ is higher than the F2 of /i/ $(2009 \mathrm{~Hz})$. Perceptually, a striking difference between $/ \mathbf{i} /$ and $/ \mathbf{i} /$ is the frication present in $/ \mathbf{i} /$. Figure 10 exhibits narrow band spectrograms of $/ \mathrm{ti}^{3} /(10 \mathrm{a})$ and $/ \mathrm{ti}^{3} /(10 \mathrm{~b})$. Harmonics can be clearly identified in $/ \mathrm{ti}^{3} / \mathrm{but}$ are not in $/ \mathrm{ti}^{3} /$, especially in the frequency bands above $2 \mathrm{kHz}$. Furthermore, there is a substantial amount of aperiodic energy in the higher frequency region, particularly above $4 \mathrm{kHz}$ in $/ \mathrm{ti}^{3} /$, which suggests the presence of strong fricative noise. This observation is further confirmed by the HNR (Harmonics-to-Noise Ratio) results, with $/ \mathrm{i} / \mathrm{in}^{\mathrm{i}} / \mathrm{ti}^{3} /(8.1 \mathrm{~dB})$ showing more noise than $/ \mathrm{i} /$ in $/ \mathrm{ti}^{3} /(9.8 \mathrm{~dB})$. 
(a)

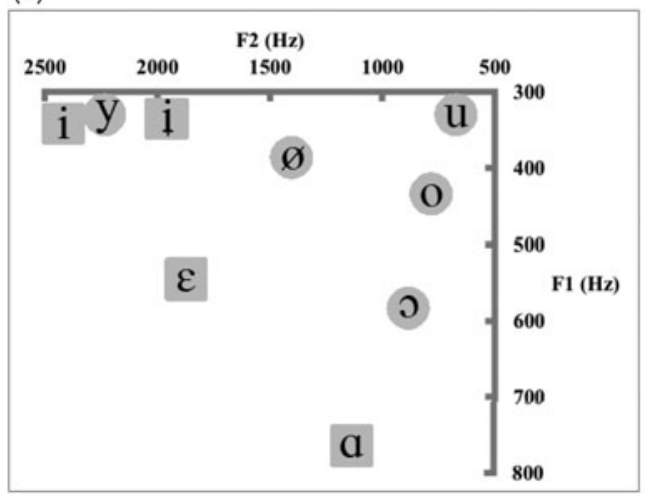

(b)

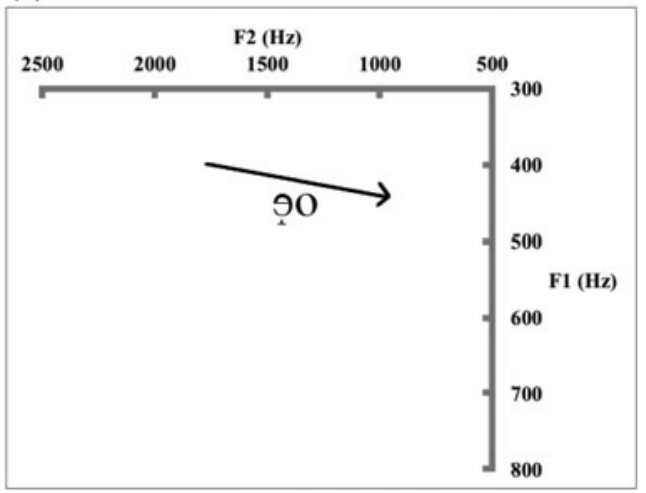

Figure 7 The F1-F2 values of monophthongs and diphthong in open syllables: (a) monophthongs; (b) diphthong. Squares represent unrounded vowels; circles represent rounded vowels. The arrow demonstrates the trajectory of the gliding.

(a)

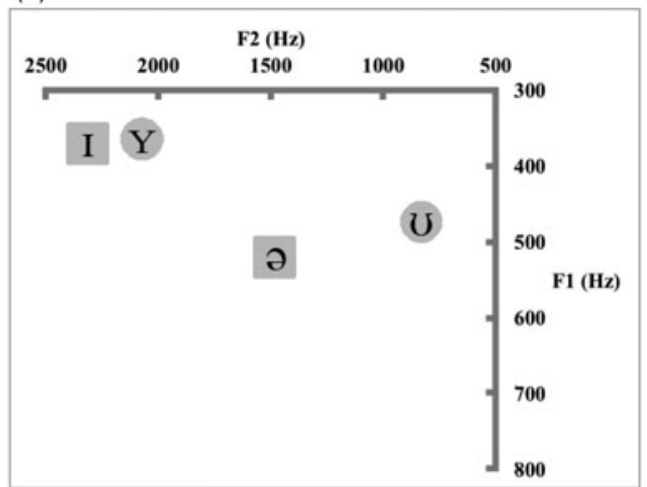

(b)

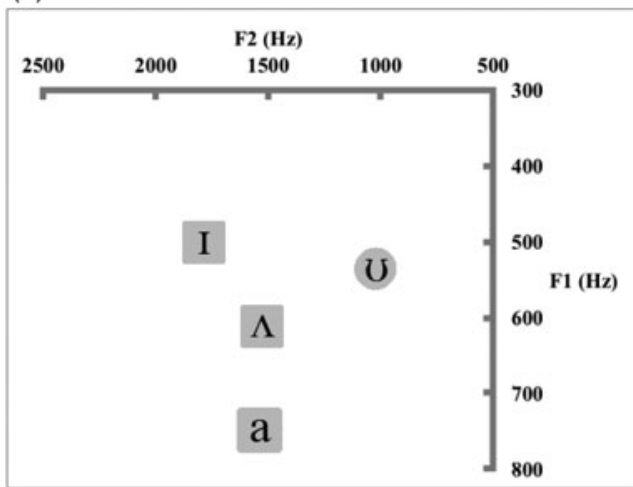

(c)

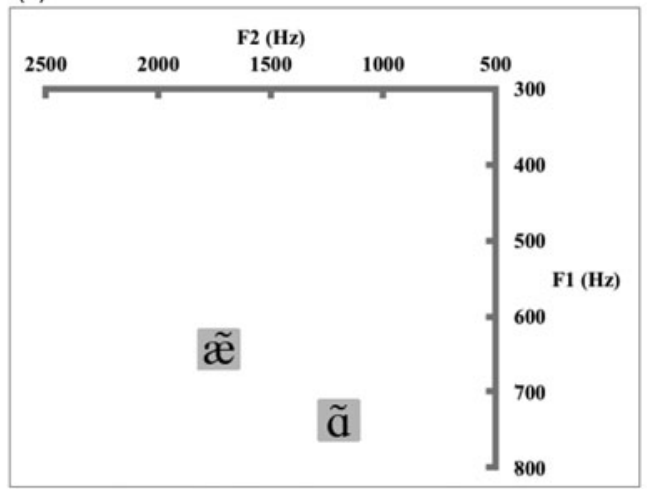

Figure 8 The F1-F2 values of monophthongs in closed syllables and nasalized vowels: (a) vowels in syllables closed by a nasal; (b) vowels in syllables closed by a glottal coda; (c) nasalized vowels. Squares represent unrounded vowels; circles represent rounded vowels.

A similar contrast has been reported in Suzhou Wu Chinese (Chao 1928: 38; P. Wang 1987; Hu 2007; Ling 2007, 2011). In order to illustrate the frication, Ling (2011) adopted the symbol $/ i_{z} /$ for the phoneme and [3] (i.e. the syllabic laminal postalveolar voiced fricative) for its phonetic realization. However, this treatment is problematic. First, a subscript $/ \mathrm{z} /$ does 


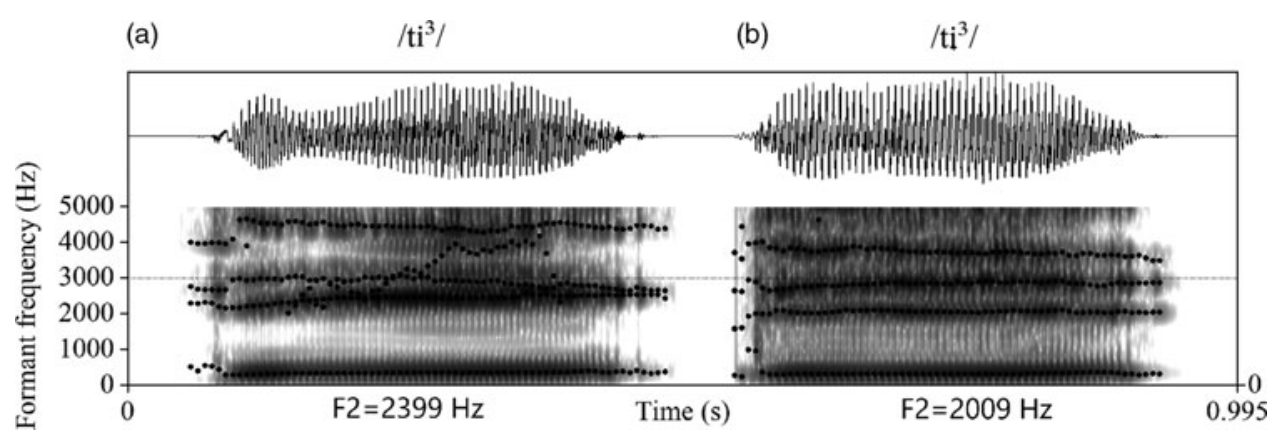

Figure 9 Waveforms and spectrograms of (a) / $/ \mathrm{ti}^{3} /$ 'dot' and (b) / $/ \mathrm{t}^{3} /$ 'bottom'. F2 values are indicated.

(a)

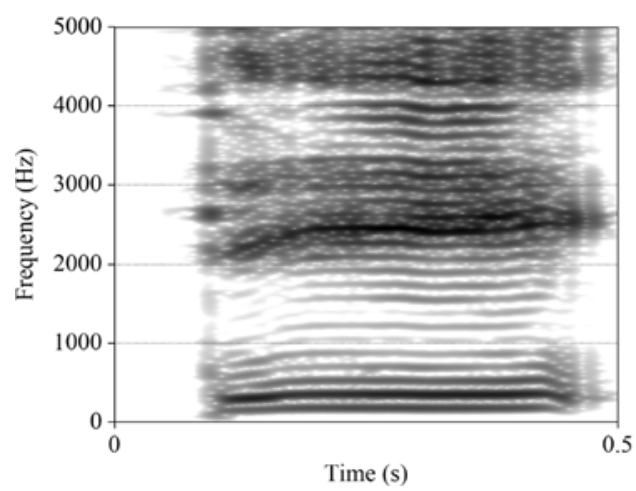

(b)

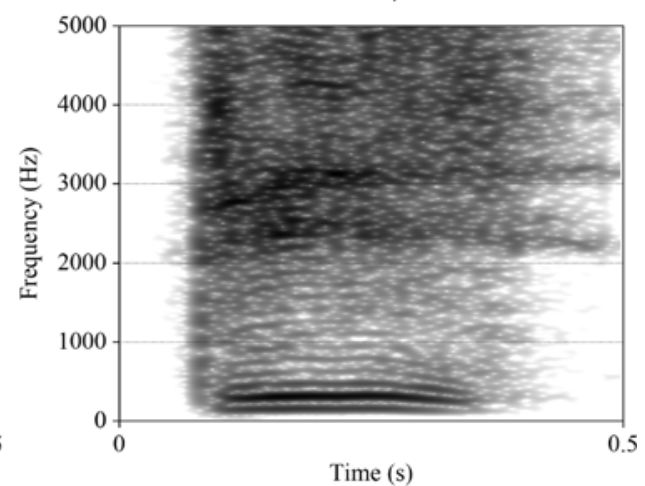

Figure 10 Narrow band spectrograms of (a) /ti $\mathbf{i}^{3} /$ 'dot' and (b) /ti $\mathbf{i}_{+}^{3} /$ 'bottom'.

not meet the convention of diacritic symbols in the IPA. Second, articulatory data (i.e. palatographic, linguagraphic, and electromagnetic articulographic studies) of Suzhou Wu Chinese have shown that the constriction of $/ \mathrm{i} /$ is located at a more anterior position (Ling 2007, 2011; $\mathrm{Hu} \&$ Ling 2019) than /i/. Consequently, the lengthening of the back resonating cavity lowers the F2 of /i/ as argued by Ling (2011) following Stevens (1989). Third, we have also noted that the frication in Lili, compared to that in Suzhou Wu Chinese, is not consistently audible for all / i / words produced by our consultant and also not as strong as that in Suzhou Wu Chinese. For instance, there is little frication in $/ \mathrm{fij}_{+}^{1} /\left[\mathrm{f}_{+}^{-}{ }_{+}^{-1}\right]$ 'to fly' (which tends to be diphthongal). Given the three reasons, we have adopted the symbol // to highlight the more anterior constriction of $/ \mathrm{i} /$ and the less friction. Such an articulatory gesture is also accompanied by the raising of the lower jaw in words such as $/ i_{+}^{1} /$ 'clothes', which however, is not observed in words such as $/ \mathrm{i}^{1} /$ 'smoke', as shown in the video recordings. The contrast of high front vowels between $/ \mathrm{i} /$ and $/ \mathrm{i} /$ is an areal feature in many Chinese dialects, especially in the Jianghuai Mandarin family (江淮官话) (R. Shi 1998, Zhu 2004b, Zhao 2007). Similar contrasts have also been argued to occur in modern African languages, such as Len Mambila (Connell 2007) and Ring languages (Faytak \& Merrill 2015).

Both $/ \mathrm{u} /$ (in $/ \mathrm{u}^{1 /}$ 'crow') and /o/ (in $/ \mathrm{ko}^{1 /}$ 'melon') are close/closed-mid back monophthongs with compressed lip rounding. The lips for $/ \mathrm{o} /$ are more protruding but for $/ \mathrm{u} /$ they are less rounded and more compressed (similar to the $/ \mathrm{u}$ o/ contrast in Shanghainese as discussed 
in Chen \& Gussenhoven 2015). After bilabial and labio-dental, ${ }^{4} / \mathrm{u} /$ is produced as [v] (i.e. the syllabic labiodental voiced fricative), as exemplified in $/ \mathrm{pu}^{1} /\left[\mathrm{pv}^{1}\right]$ 'wave'. After alveolar, alveolo-palatal and velar consonants, $/ \mathrm{u} /$ is realized with diphthong quality (i.e. [əu]), as shown in $/ \mathrm{ku}^{1} /\left[\mathrm{kou}^{1}\right]$ 'song'. According to a Suzhounese syllabary named $A$ Syllabary of the Soochow Dialect, recorded by A Committee of the Soochow Literary Association (1892) for missionaries in acquiring Suzhounese, such a diphthongal realization of $/ \mathrm{u} /$ after alveolar, alveolo-palatal and velar consonants can be traced back to the beginning of the 20th century.

The front vowel $/ \varnothing /$ tends to be produced with a lower F2 such as in $/ \varnothing^{1} /\left[? \ddot{\varnothing}^{1}\right]$ 'in safe' $(1228 \mathrm{~Hz})$ than in $/ \mathrm{j} \varnothing^{2} /\left[ч \varnothing^{2}\right]$ 'rounded' $(1425 \mathrm{~Hz})$. Both, however, are produced with a lip rounding gesture, as shown in the video recordings.

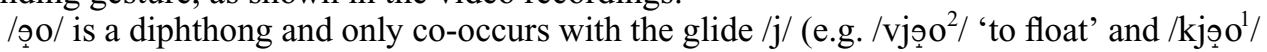
'to tick off') or alveolo-palatals (e.g., /dz9 $0^{6} /$ 'used' and $/ 69_{2} 0^{1 /}$ ' to rest').

Vowels preceding a glottal stop coda show a much shorter duration. When high vowels (i.e. $/ \mathrm{I} /$ and $/ \mathrm{U} /$ ) occur before $/ \mathrm{R} /$, a general displacement towards an open back position

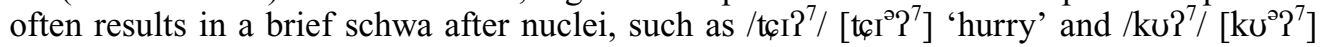
'surname, Guo'.

$/ \tilde{\mathfrak{x}} /$ and $/ \tilde{\mathbf{a}} /$ are two nasalized vowels, as illustrated in $/ \mathrm{ts}^{\mathrm{h}} \tilde{\mathfrak{x}}^{6} /$ 'unimpeded' and $/ \mathrm{ts}^{\mathrm{h}} \tilde{\mathbf{a}}^{6} /$ 'to sing'. Both vowels are consistently nasalized without recognizable velum closure in Lili Wu Chinese, different from the case of Shanghainese where a brief velar nasal coda has been reported (Chen \& Gussenhoven 2015).

\section{Syllabic approximants}

There are two syllabic approximants in Lili Wu Chinse, which are exemplified in $/ \mathrm{sI}_{1}^{1} /\left[\mathrm{s} \mathrm{s}_{1}^{1}\right.$ ]

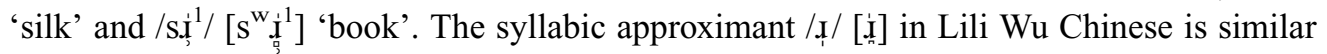
to that in Standard Chinese.

With respect to $/ \mathrm{I} /$, two features are to be further noted. First, the lip rounding gesture of the approximant contributes to the labialization of the preceding alveolar sibilant onset (i.e. $/ \mathrm{s} /\left[\mathrm{s}^{\mathrm{w}}\right]$ before $/ \mathrm{i} /$ ). Labialized alveolar sibilants are rare in the world's languages (but see Lao, a Tai-Kadai language reported in Erickson 2001). The rounding feature is believed to evolve from $/ \mathrm{u} /$ or $/ \mathrm{y} /$, the two rounded vowels reported to be present instead of $/ \mathrm{i} / \mathrm{in}$ other Wu dialects, such as $/ \mathrm{su}^{1} /$ in Danyang (丹阳) Wu and $/ 6 \mathrm{y}^{1} /$ in Songjiang (松江) Wu for 'book' (Qian 1992: 88). In addition, / I, / is articulated more laminally. Laminal consonants have been widely reported to exist in Australian languages (Butcher 1990, Anderson \& Maddieson 1994). Such an articulatory gesture of / $/ \dot{\mathrm{I}} /$ is reflected in Figure 11 as a lowered F4 ( $3375 \mathrm{~Hz}$, compared to $4221 \mathrm{~Hz}$ of $/ \mathrm{I} / \mathrm{in} / \mathrm{SI}_{1}{ }^{1}$ ) and the proximity of F3 and F4. F4 lowering is generally said to be related to articulatory retraction (e.g. Fant 1960: 121; Stevens \& Blumstein 1975; Vaissière 2011). The proximity of F3 and F4 is known as a consequence of weakly coupled resonators by forming a relatively larger frontal cavity (Stevens 1989). For instance, a significant convergence of F3 and F4 is observed in laminal alveolar and postalveolar fricatives in English, as well as in apico-laminal alveolars in French (Dart 1991: 104). In short, /II / is produced with a more laminal articulation combined with a lip rounding gesture than its counterpart $/ \mathrm{I} /$. Such differences were also noticed by our consultant who offered his native intuition voluntarily with us. Given the impressionistic nature of the description, needless to say, more instrumental studies (e.g. ultrasound) are needed for a precise description of their articulation and acoustic consequences.

It is worth noting that there exist different proposals to transcribe these sounds. For example, among sinologists (after Karlgren 1915: 294), /I/ and /it/ have often been transcribed as $/ \mathrm{I} /$ and $/ \mathrm{Y} /$, respectively, and are known as 'apical vowels'. $/ \mathrm{I} /$ is sometimes treated as $[\mathrm{Z}]$

\footnotetext{
${ }^{4}$ The $/ \mathrm{mu} /$ syllable is quite limited. Only one word $/ \mathrm{mu}^{3} /\left[\mathrm{mov}^{3}\right]$ 'bound morpheme for the literary address of mother' has been found in Lili Wu Chinese. The realization of $/ \mathrm{u} /$, however, patterns with that after alveolar and velar consonants.
} 


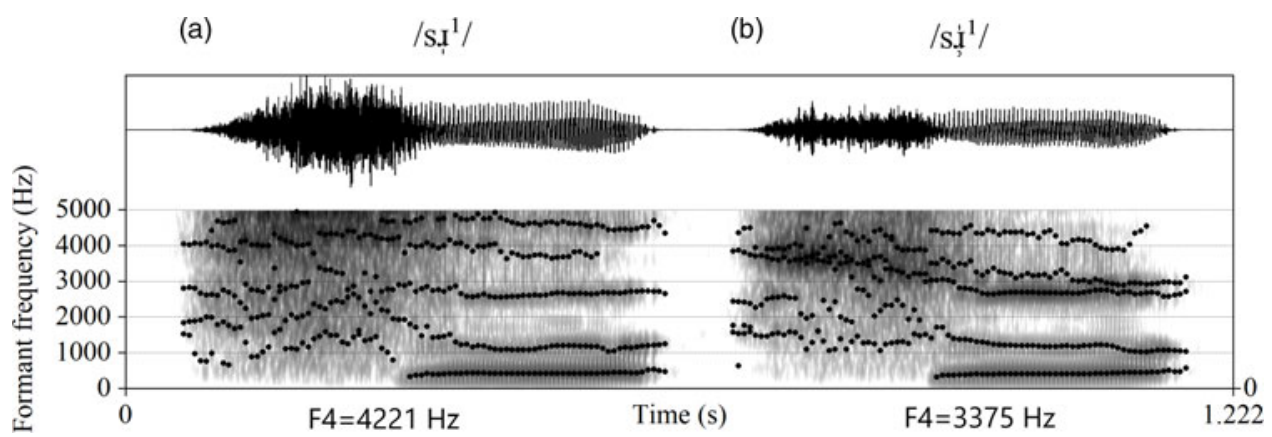

Figure 11 Waveforms and spectrograms of (a) /s.t1/ 'silk' and (b) /s.t1/ 'book'. F4 values are indicated.

(e.g. Ladefoged \& Maddieson 1996: 314; Wiese 1997: 239; Duanmu 2000: 36 for Standard Chinese; Chen \& Gussenhoven 2015 for Shanghainese). Such a treatment, however, has been questioned with ultrasound imaging data (Lee-Kim 2014, Faytak \& Lin 2015) and acoustic analyses (Howie 1976: 10). Lee-Kim (2014) further argues that it is more appropriate to describe $[\mathrm{z}]$ as 'dental approximant $\left[\mathrm{It}_{-}\right]$'. ${ }^{5}$ A similar treatment can also be found in Lee \& Zee (2003).

Last but not least, an increasing body of literature has shown that such syllabic approximants are known to affect diachronic changes of high vowels in different languages at different time points, across an overwhelmingly large number of Sino-Tibetan languages (e.g. Baron 1974, R. Shi 1998, Zhu 2004b, Zhao 2007, Hu \& Ling 2019).

\section{Syllable structure}

Generally speaking, eight syllable combinations can be identified in Lili Wu Chinese. The canonical syllable minimally consists of an obligatory nucleus (V) and a lexical tone as in $/ u^{1} /$ 'crow' and $/ \varnothing^{2} /\left[\mathrm{C}^{2}\right]$ 'cold'. The nucleus can be either a vowel or a syllabic consonant (i.e. I I $\mathrm{m}$ ì/). ${ }^{6}$ It may also contain up to three optional elements in the following linear structure: $\left(C_{1}\right)(G) V\left(C_{2}\right)$, where $C_{1}$ can be any consonant in the consonant inventory except for $/ 2 /$, G is either $/ \mathrm{j} /$, as in $/ \mathrm{kjogo}^{1} /$ 'to tick off', or $/ \mathrm{w} /$, as in $/ \mathrm{kw}^{1 /}$ / 'to close'; $\mathrm{C}_{2}$ is either $/ \mathrm{y} /$ or $/ \mathrm{P} /$ as in $/ \mathrm{kuy}^{1 /}$ ' public' and $/ \mathrm{kaP}^{7} /$ 'to clip'. Parentheses indicate optional constituents. All combinations are demonstrated in Table 3.

Table 3 Syllabic combinations in Lili Wu Chinese.

\begin{tabular}{|c|c|c|c|c|c|c|}
\hline Combination & Examples & & & & & \\
\hline V & $/ u^{1 /}$ & 乌 & 'crow' & $10^{2} /$ & 寒 & 'cold' \\
\hline GV & $/ \mathrm{wo}^{4} /$ & 坏 & 'broken' & $/ \mathrm{j} \varnothing^{2} /$ & 圆 & 'rounded \\
\hline$C_{1} V$ & $/ \mathrm{zo}^{1 /}$ & 柴 & 'firewood' & $/ \mathrm{ka}^{1} /$ & 高 & 'high' \\
\hline $\mathrm{VC}_{2}$ & $/ \mathrm{un}^{1 /}$ & 翁 & 'surname, Weng' & $/ \mathrm{a}^{8} /$ & 盒 & 'box' \\
\hline$C_{1} G V$ & /kjọo ${ }^{1 /}$ & 勾 & 'to tick off' & $/ \mathrm{kw} \varepsilon^{1 /}$ & 关 & 'to close' \\
\hline$C_{1} V C_{2}$ & $/ \mathrm{kuy}^{1} /$ & 公 & 'public' & $/ \mathrm{kaP}^{7} /$ & 夹 & 'to clip' \\
\hline $\mathrm{GVC}_{2}$ & $/ \mathrm{jun}^{2} /$ & 熊 & 'bear' & $/ \mathrm{w} \Lambda \mathrm{P}^{7} /$ & 活 & 'alive' \\
\hline$C_{1} G V C_{2}$ & $/$ njun $^{1 /}$ & 浓 & 'strong (taste or smell)' & $/ \mathrm{kw} \Lambda \mathrm{P}^{7} /$ & 国 & 'country' \\
\hline
\end{tabular}

\footnotetext{
5 In Lee-Kim (2014: 264), the syllabic diacritic is not used for the sake for simplicity.

6 In Lili Wu Chinese, /, it/ are obligatory to contain an onset.
} 
As illustrated in Table 4, co-occurrence constraints on onset and rhyme combinations can be observed. First, /i in I? i/ behave similarly except that /i/ can appear after labio-dentals as in $/ \mathrm{fi}_{+}^{1} /$ ' to fly' and $/ \mathrm{vi}_{+}^{2} /$ 'fat'. /i/, on the other hand, is prohibited in this context (i.e. */fi/, */vi/). Second, /y Yy/ are only allowed after alveolar sonorants and alveolo-palatals, or without an

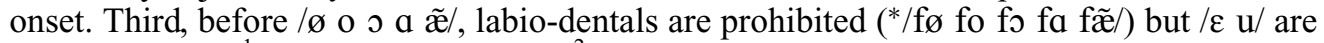
possible as in $/ \mathrm{f}^{1} /$ 'to turn over' and $/ \mathrm{vu}^{2} /$ 'to support somebody with one's arm'. Fourth, the two syllabic approximants /. I I / $/$ occur only after alveolar homorganic sibilant onsets $/ \mathrm{ts}^{\mathrm{h}} \mathrm{s}^{\mathrm{h}} \mathrm{d}$ $\mathrm{S} \mathrm{z} /$. $/ \mathrm{j} \mathrm{w} /$ can serve as an onset as in $/ \mathrm{j}^{2} /$ 'rounded' and $/ \mathrm{wo}^{4} /$ 'broken'.

The distribution of the two glides is summarized in Table $5 . / \mathrm{j} /$ is allowed in the majority of cases (e.g. $/ \mathrm{pja}^{1} /$ 'watch', $/ \mathrm{vjọo}^{2} /$ 'to float', $/ \mathrm{tja}^{1} /$ 'marten', $/ \mathrm{kjọo}$ / / to tick off', $/ \mathrm{hjọo}^{3} /$ 'to roar' and /jø / 'rounded') except after alveolo-palatals. /w/, however, is more constrained and only allowed after velars (e.g. $/ \mathrm{kw}^{1} /$ ' to close'), glottal fricative $/ \mathrm{h} /$ (e.g. /hw $\varepsilon^{1} /$ 'dust'), or serves as a glide onset (e.g. /we $\varepsilon^{2}$ 'to be back').

Table 4 Observed onset-rhyme combinations.

\begin{tabular}{|c|c|c|c|c|c|c|c|}
\hline Onset & i I $\mathrm{I}$ ? & $\stackrel{\mathrm{i}}{+}$ & $\mathrm{y} \mathrm{yn}$ & $\begin{array}{l}\varepsilon \text { u ã } u \eta \\
\partial \eta \text { a } \tilde{P} \\
\Lambda ?\end{array}$ & $\begin{array}{l}\varnothing 000 \\
\text { a } \tilde{\dddot{x}}\end{array}$ & II İ & $\bigodot_{\perp} \mathrm{O}$ \\
\hline Bilabial ( $\mathrm{p}^{\mathrm{h}} \mathrm{p}$ b m) & YES & YES & NO & YES & YES & NO & NO \\
\hline Labio-dental (f v) & NO & YES & NO & YES & NO & NO & NO \\
\hline Alveolar plosives $\left(\mathrm{t}^{\mathrm{h}} \mathrm{t} \mathrm{d}\right)$ & YES & YES & NO & YES & YES & NO & NO \\
\hline Alveolar sonorants (n 1) & YES & YES & YES & YES & YES & NO & NO \\
\hline Alveolar sibilants (ts ${ }^{\mathrm{h}}$ ts $\mathrm{z} \mathrm{s} \mathrm{z}$ ) & YES & YES & NO & YES & YES & YES & NO \\
\hline Alveolo-palatal ( $\mathrm{t}^{\mathrm{h}}$ tc $\left.\mathrm{d}, \mathrm{c}\right)$ & YES & YES & YES & YES & YESC & NO & YES \\
\hline Velar and glottal ( $\left.\mathrm{k}^{\mathrm{h}} \mathrm{k} \mathrm{g} \mathrm{h} \mathrm{j}\right)$ & NO & NO & NO & YES & YES & NO & NO \\
\hline $\mathrm{j}$ & NO & NO & NO & YES $^{d}$ & YES ${ }^{e}$ & NO & YES \\
\hline $\mathrm{W}$ & NO & NO & NO & YES & YES ${ }^{f}$ & NO & NO \\
\hline Zero onset & YES & YES & YES & YES & YES & NO & NO \\
\hline \multicolumn{8}{|l|}{ a /nyy/ and /lyy/ cannot be observed. } \\
\hline \multicolumn{8}{|l|}{$\mathrm{b} / \mathrm{tc}^{\mathrm{h}} \mathrm{tc} \mathrm{d}_{\varphi} \mathrm{c} /+/ \varepsilon \mathrm{u}$ əy/ cannot be found. } \\
\hline \multicolumn{8}{|l|}{$\mathrm{c} / \mathrm{tc}^{\mathrm{h}}$ tc $\mathrm{d}_{\mathrm{c}} \mathrm{c} /+\mathrm{o} / \mathrm{o}$ cannot be found. } \\
\hline \multicolumn{8}{|l|}{ d/je/, /ju/, and /jəy/ cannot be observed. } \\
\hline e/jo/ cannot be found. & & & & & & & \\
\hline $\mathrm{f} / \mathrm{wu} /, / \mathrm{w} ø /$, and /wa/ cannot be foun & & & & & & & \\
\hline
\end{tabular}

Table 5 Observed onset-glide combinations.

\begin{tabular}{lcc}
\hline Onset & $\mathrm{j}$ & w \\
\hline Bilabial & YES & NO \\
Labio-dental & YES & NO \\
Alveolar & YES & NO \\
Alveolo-palatal & NO & NO \\
Velar and Glottal & YES & YES \\
Glottal & YES & YES \\
Glide onset & YES & YES \\
\hline
\end{tabular}




\section{Onsetless syllables}

In onsetless syllables with high-register tones (i.e. T1, T3, T5, and T7), the phonetic segment [?] can be observed at the onset of the tone-bearing syllable, as in $/ \varnothing^{1} /\left[? \ddot{\varnothing}^{1}\right.$ ] 'in safe' and $/ \mathrm{si}^{1}$ $\varnothing^{1 /}\left[s_{+}^{44} 2 \ddot{ø}^{42}\right]$ 'a city, Xi'an'. With respect to onsetless syllables with low-register tones (i.e. T2, T4, T6, and T8), we observe phonetic realization of [6] before a non-high vowel (e.g. $/ \varnothing^{2} /$ [hö $\left.{ }^{2}\right]$ 'cold', $/ \mathrm{J}^{2} /\left[\mathrm{ho}^{2}\right]$ 'shoes', and $/ \mathrm{aP}^{8} /\left[\mathrm{ha}^{8}{ }^{8}\right]$ 'box'), in contrast to the cases when there is a high vowel or glide (e.g. $/ \mathrm{i}^{2} /\left[\mathrm{ji}^{2}\right]$ 'salt', /jø $\varnothing^{2} /\left[\mathrm{\varphi}^{2}\right]$ 'rounded', $/ \mathrm{u}^{2} /$ 'river', and $/ \mathrm{w} \Lambda \mathrm{P}^{8} /$ 'alive'). [6] disappears in non-initial position within a prosodic word, e.g. $/ \mathrm{t}^{\mathrm{h}} \mathrm{a}^{4} \mathrm{o}^{2} /$ 'galoshes'. The general pattern is therefore similar to Shanghainese (Chen \& Gussenhoven 2015).

In Lili $\mathrm{Wu}$ Chinese, syllables with low-register tones show relatively stronger breathiness than those with high-register counterparts. As indicated by Figure 12, the Fast Fourier Transform (FFT) spectrum of $/ \varnothing^{1} /\left[? \ddot{\varnothing}^{1}\right]$ 'in safe' (dark) and $/ \varnothing^{2} /\left[\right.$ [h $\left.\ddot{\varnothing}^{2}\right]$ 'cold' (light) shows the phonation contrast in the vowel /ø/, taken within an interval of approximately $30 \mathrm{~ms}$ from the first regular vocal pulse of the vowel. As shown by the measurements on $\mathrm{H} 1-\mathrm{H} 2$ (i.e. amplitude difference between the first and second harmonics), there is a phonatory difference between the two vowels with $/ \varnothing^{2} /(4.5 \mathrm{~dB})$ showing more breathiness than $/ \varnothing^{1} /(2 \mathrm{~dB})$. This contrast has also been observed in other Northern Wu dialects (Cao \& Maddieson 1992).

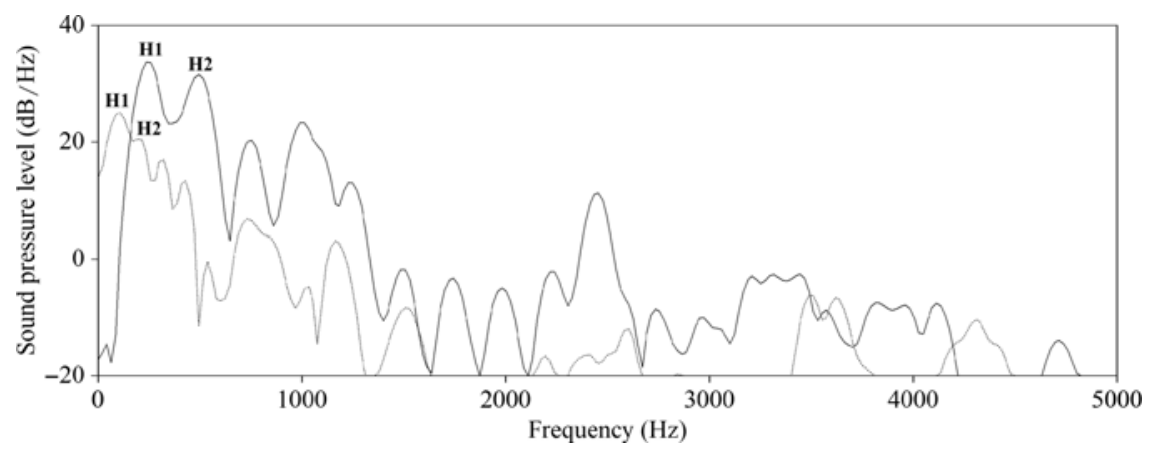

Figure $12 \mathrm{FFT}$ spectrum of $/ \varnothing /$ in $/ \varnothing^{1 / /}$ 'in safe' (dark) and / $/ \varnothing^{2} /$ 'cold' (light) over an interval of approximately $30 \mathrm{~ms}$ from the first regular vocal pulse of the vowel. The first two harmonics ( $\mathrm{H} 1$ and $\mathrm{H} 2$ ) of each syllable are indicated.

\section{Tone sandhi: A preliminary overview}

Lexical tones over monosyllabic morphemes undergo changes when they are combined into compounds or phrases. In this description, we offer some preliminary observations concerning tone sandhi variations in Lili Wu Chinese over disyllabic compounds (hereafter called the tone unit). Tonal realization is mainly contingent upon the lexical tone of the second syllable $\left(\sigma_{2}\right)$. Generally speaking, two general patterns are observed.

First, when $\sigma_{2}$ carries an abrupt tone (i.e. T7 and T8 over a glottal-coda syllable), regardless of the syllable structure of the first syllable $\left(\sigma_{1}\right)$, only level f0 contours surface, and the specific f0 height is dependent on the lexical tone of $\sigma_{1}$. After a high tone, a low tone appears; while after a low tone, a high tone appears. Both patterns are illustrated in Figure 13, which

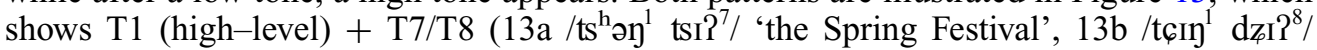
'Peking Opera') and T6 (low-level) + T7/T8 (13c/th ${ }^{6} \mathrm{kw} \Lambda ?^{7} /$ 'Thailand', 13d / $/ \mathrm{tc}^{\mathrm{h}_{\mathrm{i}}}{ }_{+}^{6} \mathrm{dI}^{2}{ }^{8} /$ 'steam whistle').

Second, when $\sigma_{2}$ carries a non-abrupt tone (i.e. T1 to T6 over an open syllable or a syllable with a nasal coda), the lexical tonal contour of $\sigma_{1}$ remains and affects the pitch 
(a)

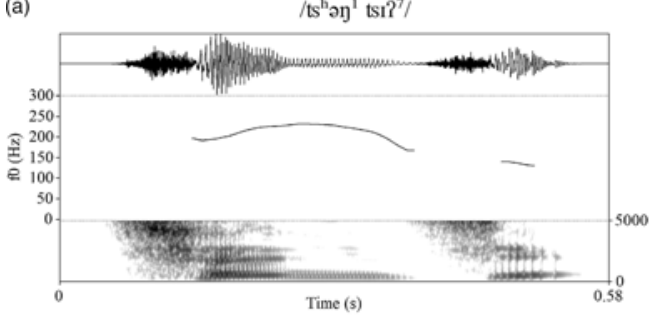

(c)

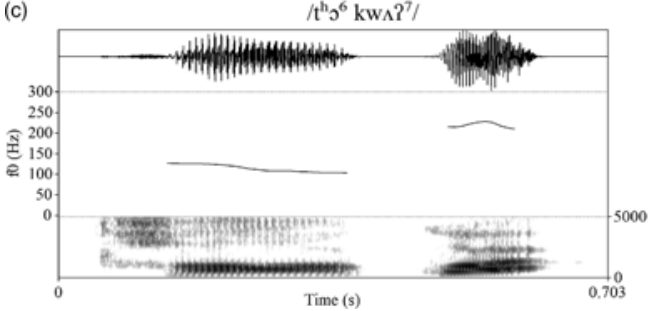

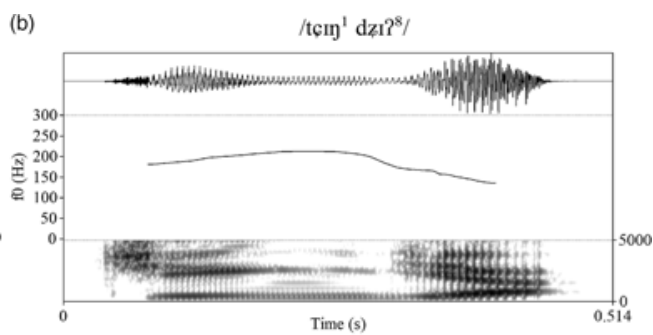

(d)

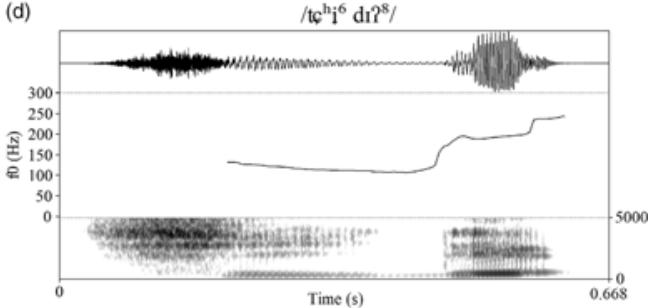

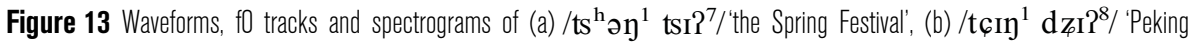
Opera', (c) / $\mathrm{t}^{\mathrm{h}} \rho^{6} \mathrm{kw} \Lambda 2^{7} /$ 'Thailand', and (d) $/ \mathrm{tc}_{6}{ }^{\mathrm{h}_{\mathrm{i}} 6} \mathrm{di}^{8} /$ / steam whistle'.

(a)

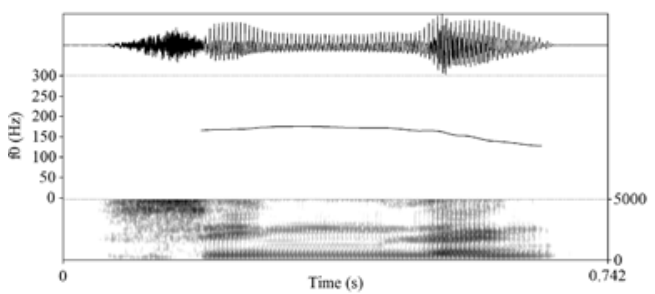

(c)

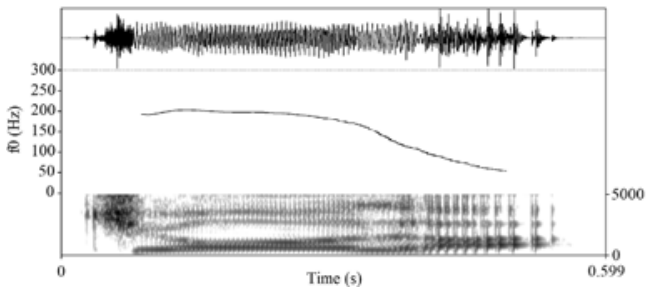

(b)

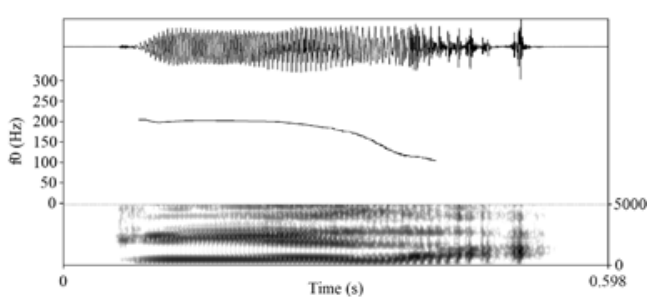

(d)

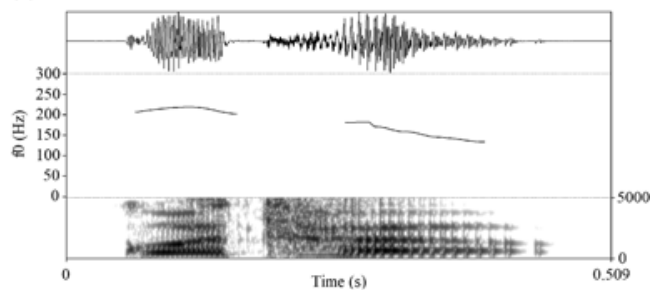

Figure 14 Waveforms, fo tracks and spectrograms of (a) $/ \sin ^{1} \mathrm{zo \eta}^{4} /$ 'new kidney', (b) $/ \mathrm{kg}^{3} \mathrm{za}^{4}$ / 'to remold', (c) $/ \mathrm{t} 6 \mathrm{O}^{5} \mathrm{za}^{4} /$ 'introduction', and (d) $/ \mathrm{kvP}^{7} \mathrm{t}^{\mathrm{h}} \mathrm{u}^{4} /$ 'territory'.

realization of $\sigma_{2}$. The specific f0 contour of $\sigma_{2}$ hinges upon the lexical tonal register of $\sigma_{1}$. When $\sigma_{1}$ is produced with a high-register tone (i.e. T1, T3, T5, and T7), $\sigma_{2}$ is typically realized with a falling f0 contour, as shown in Figure 14 (e.g. 14a $/ \sin ^{1} \mathrm{z}^{4} \eta^{4} /$ 'new kidney', $14 \mathrm{~b}$ $/ \mathrm{ke}^{3} \mathrm{za}^{4} /$ 'to remold', $14 \mathrm{c} / \mathrm{t} 65^{5} \mathrm{za}^{4} /$ 'introduction', and $14 \mathrm{~d} / \mathrm{kuP}^{7} \mathrm{t}^{\mathrm{h}} \mathrm{u}^{4} /$ 'territory'). However, other patterns have also been observed. For example, in the combination of T7 $+\sigma_{2}$, when $\sigma_{2}$ bears T1 (e.g. $/ \mathrm{ku}^{7} \mathrm{k}^{\mathrm{h}} \mathrm{u}^{1} /$ 'orthopaedics'), the underlying form of T1 in $/ \mathrm{k}^{\mathrm{h}} \mathrm{u}^{1} /$ (high-level) is preserved, instead of a predictable falling contour like $/ \mathrm{t}^{\mathrm{h}} \mathrm{u}^{4} /$ in $/ \mathrm{ku} ?^{7} \mathrm{t}^{\mathrm{h}} \mathrm{u}^{4} /$ 'territory'. 
When $\sigma_{1}$ is pronounced with a low-register tone (i.e. T2, T4, T6, and T8), the sandhi pattern tends to be more complicated. The tonal contour of $\sigma 2$ seems to also exert influence on the overall tonal realization. For example, Figure 15 shows the contrast of $/ \mathrm{p}^{\mathrm{h}} \mathrm{\rho}^{6} \mathrm{t} \mathrm{c}^{\mathrm{h}} \mathrm{i}^{4} /$ 'to dispatch' (15a) vs. $/ \mathrm{tc}^{\mathrm{h}} \mathrm{i}^{6} \mathrm{p}^{\mathrm{h}} \mathrm{a}^{6} /$ 'bubble' (15b). Here, T4 in $/ \mathrm{tc}^{\mathrm{h}} \mathrm{i}^{4} /$ completely loses its underlying form (low-level) and is realized with a high-falling contour, similar to Shanghainese (Chen \& Gussenhoven 2015). However, the lexical tone of the preceding tone T6 in $/ \mathrm{p}^{\mathrm{h}} \mathrm{a}^{6} /$ (low-dipping) is only preserved to a certain extent. The same tone (i.e. T6) is realized with an audible pitch level difference: T6 in $/ \mathrm{p}^{\mathrm{h}} \mathrm{o}^{6} \mathrm{tc}_{6}^{\mathrm{h}} \mathrm{i}^{4} /$ is overall lower than that in $/ \mathrm{tc}^{\mathrm{h}} i_{+}^{6} \mathrm{p}^{\mathrm{h}} \mathrm{a}^{6} \%$

(a)

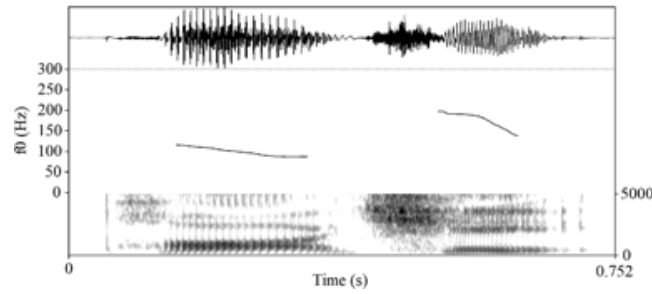

(b)

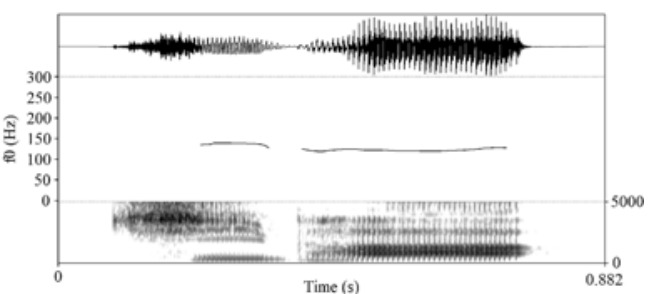

Figure 15 Waveforms, fo tracks and spectrograms of (a) $/ \mathrm{p}^{\mathrm{h}} \mathrm{o}^{6} \mathrm{t} \mathrm{c}^{\mathrm{h}} \mathrm{i}^{4} /$ 'to dispatch', and (b) $/ \mathrm{tc}^{\mathrm{h}} \mathrm{i}_{+}^{6} \mathrm{p}^{\mathrm{h}} \mathrm{a}^{6} /$ 'bubble'.

In addition, it is worth noting that syllables with aspirated onsets show two different patterns of changes. They pattern either with syllables that have unaspirated onsets and carry T1, or with syllables that have voiced onsets and carry T4, T6, or T8. For example, the sandhi change of $/ \mathrm{ts}^{\mathrm{h}} \mathrm{In}^{1} \mathrm{ZJI}^{6} /$ 'in person' patterns with that of $/ \sin ^{1} \mathrm{z} \tilde{\mathrm{a}}^{6} /$ 'heart'; while $/ \mathrm{ts}^{\mathrm{h}} \Lambda^{8} \mathrm{djọ}^{2} /$ 'to stand out' patterns with $/ \mathrm{z \Lambda}^{8}$ djơ $\mathrm{o}^{2} /$ 'tongue'.

It is important to conclude here that even within the arguably simplest construction beyond a monosyllabic morpheme (i.e. disyllabic compounds), Lili Wu Chinese already exhibits different patterns of tonal realization from its neighboring Northern $\mathrm{Wu}$ dialects such as Shanghainese (Chen \& Gussenhoven 2015). It is not only subject to the influence of the preceding tone on tonal realization, but also seems sensitive to tonal properties of the second syllable. In this illustration, we have just presented a preliminary glimpse into the pitch contours of disyllabic compounds in Lili Wu Chinese. Needless to say, more data and further research are needed.

\section{Transcription of recorded passage 'North Wind and the Sun'}

The passage is transcribed phonemically, using the symbols presented in the vowel and consonant charts. Tones have been transcribed phonemically before ${ }^{-}$(with pitch levels for the eight tonal categories provided in the section on lexical tones). Listeners will find significant deviation in the actual pitch contours of these lexical tones due to contextual tonal variation (see Chen 2012 for a comprehensive review on tonal variation). Given the salient feature of tone sandhi in Lili Wu Chinese (and generally speaking in Wu dialects), we have also provided a transcription of tonal contours based on perceptual impressions of the pitch levels according to Chao's system (after ${ }^{-}$). For personal pronouns and modal particles, only actual pitch contours have been transcribed. The boundaries between syllables are indicated by spaces. The boundaries of tone units are marked by parentheses, with $\mid$ marking the end of major phrases and $\|$ that of utterances. Our consultant tends to produce more creakiness in running speech. For example, creaky voice can be identified at the end of $/ \mathrm{k}^{\mathrm{h}} \varnothing^{213} /$ 'to look' in 
$/ \mathrm{pi}_{+}^{53-53} \mathrm{pi}_{+}^{53-31} \mathrm{k}^{\mathrm{h}} \mathscr{Q}^{213-44} /$ 'make a comparison (a bit, as an attempt)' with a sudden rise of $\mathrm{f} 0$. Worth noting that segmental reduction usually happens in running utterance. For example, $/ \mathrm{A} /$ is sometimes reduced to [ə]. [] marks the (allophonic) cases that auditorily deviate saliently from the phonemic transcription.

\section{Phonemic transcription}

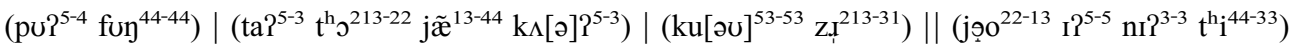

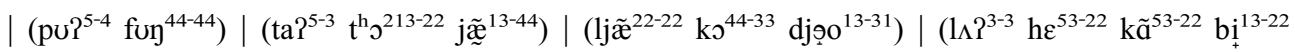

$$
\begin{aligned}
& \left.\mathrm{dja}_{\sim}^{13-33}\right)\left\|\left(\mathrm{lo}^{3}\right)\left(\mathrm{z}^{13-13} \mathrm{ja}^{423-33} \mathrm{u}^{213-22}\right) \mid\left(\mathrm{zI}^{213-22} \mathrm{kj}^{44-44}\right)\left(\mathrm{pə \eta}^{53-53} \mathrm{zI}^{213-31} \mathrm{du}[\partial v]^{213-22}\right)\right\|\left(\mathrm{lj} \tilde{x}^{22-22}\right.
\end{aligned}
$$

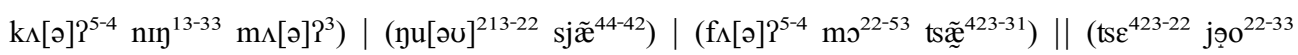

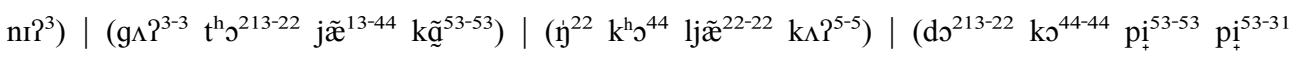

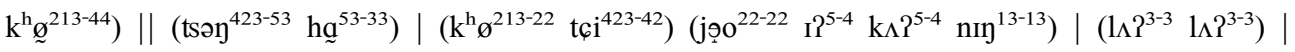

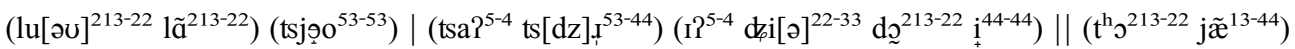

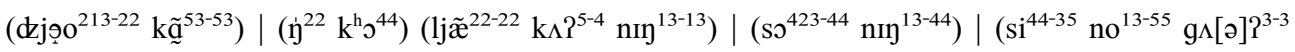

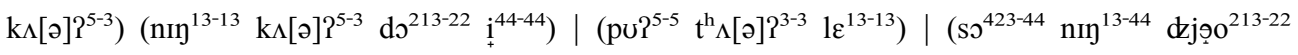

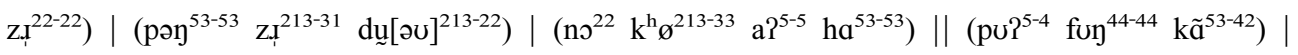

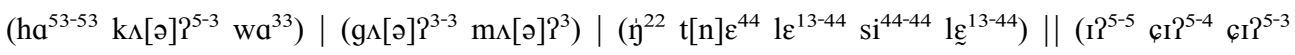

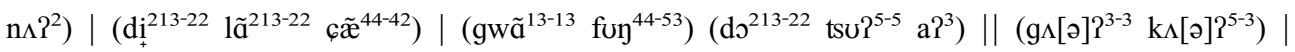

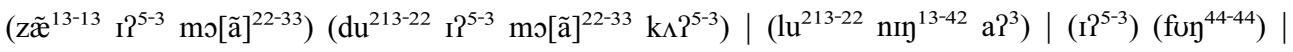

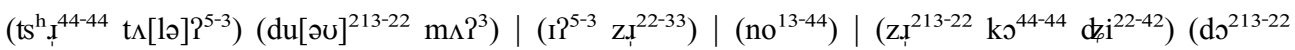

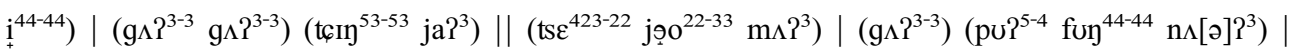

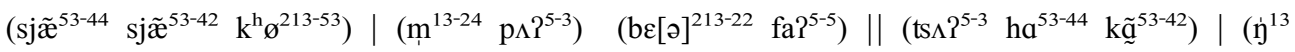

$$
\begin{aligned}
& \left.\mathrm{nu}[\partial u]^{44} \mathrm{~g} \Lambda \mathrm{P}^{3-4} \mathrm{ti}^{53-55}\right)\left(\mathrm{pə \eta}^{53-53} \mathrm{zI}^{213-31}\right)\left|\left(\mathrm{zjọ}^{213-22} \mathrm{zo}^{213-22} \mathrm{~g} \Lambda \mathrm{P}^{3-3} \mathrm{ti}^{53-55} \mathrm{ts}[\mathrm{t}] \varepsilon^{53}\right)\right|\left(\mathrm{g} \Lambda \mathrm{P}^{3-3} \mathrm{~m} \Lambda[ə] \mathrm{P}^{3}\right.
\end{aligned}
$$

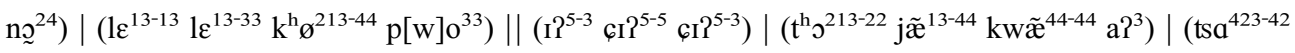

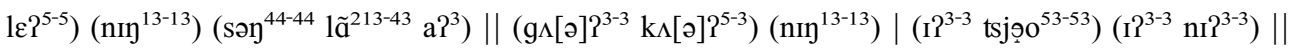

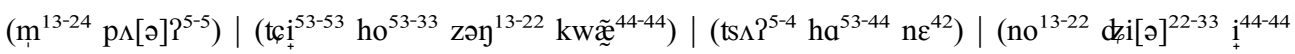

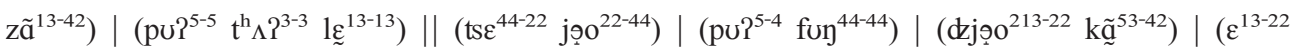

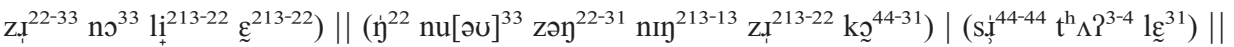




\section{Orthographic transcription}

北风搭太阳个故事。有一日天, 北风搭太阳两家头勒许讲皮条。(伊)落侪要话, 自家本 事大。两个人末, 互相弗买账。最后嗫, 䍱太阳讲, 我咖两个大家比比看。正好看见 有一个人, 勒勒路浪走, 着仔一件大衣。太阳就讲, 我咖两个人, 啥人先拿䍱个人个 大衣拨脱来, 啥人就是本事大, 㑚看阿好? 北风讲, 好个啘。掰末, 我堆来先来。一 歇歇呐, 地浪向狂风大作啊。拜个长一码大一码个路人啊, 越风吹得大末, 亦是拿自

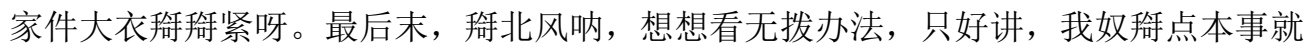
(实价 $)^{7}$ 拜点哉, 䤣末, 㑚来来看罢。一歇歇, 太阳光啊, 照勒人身浪啊。拜个人, 越 走越热, 无拨几许辰光, 只好呢, 拿件衣裳拨脱来。最后, 北风就讲, 还是 㑚厉害, 我奴承认自家输脱来。

\section{Acknowledgements}

We would like to thank our principal consultant Mr Liangquan Cheng 程良权 for making this possible. We are also grateful to Mr Haimin $\mathrm{Li}$ 李海珢 for his coordination and arrangement for the three fieldwork sessions conducted in Lili. In addition, we would like to thank Maarten Mous and Ruiqing Shen for valuable comments on earlier versions of our paper, and to Zhongmin Chen, Hang Cheng, Maarten Kossmann, Feng Ling, Zhongwei Shen, Yimin Sheng, Rujie Shi, Huan Tao, Ping Wang, Xinyi Wen, and Dan Yuan for sharing their thoughts with us on various linguistic aspects of the language, and to Feifan Wang for collecting pilot recordings, and to He Huang, Huaqiang Song, and Lei Wang for sharing references. Moreover, we gratefully acknowledge the anonymous reviewers of this journal for helpful comments and suggestions. The proofreading assistance from Seamus Leith and the audio editing guidance from André Radtke are gratefully appreciated. This work is supported by China Scholarship Council (CSC) and Leiden University Centre for Linguistics (LUCL) scholarship to the first author as well as the KNAW-China Exchange grant (13CDP012) from the Netherlands Royal Academy of Sciences to the second author. Neither the individuals and institutions cited herein nor the funding agencies, however, should be held responsible for the views expressed in this paper.

\section{Supplementary material}

To view supplementary material for this article, please visit https://oi.org/10.1017/ S0025100320000092.

\section{References}

A Committee of the Soochow Literary Association (ed.). 1892. A syllabary of the Soochow dialect. Shanghai: American Presbyterian Mission Press.

Anderson, Victoria B. \& Ian Maddieson. 1994. Acoustic characteristics of Tiwi coronal stops. UCLA Working Papers in Phonetics 87, 131-162.

Baron, Stephen P. 1974. On the tip of many tongues: Apical vowels across Sino-Tibetan. Presented at 7th International Conference on Sino-Tibetan Language and Linguistic Studies, Atlanta, Georgia State University. Retrieved from https://halshs.archives-ouvertes.fr/halshs-01400987/document.

$7 / \mathrm{z}^{6} /$ 'manner, degree and quality proximal deixis' is the coalescence of two syllables $/ \mathrm{z} \Lambda \mathrm{P}^{8} /$ 'proximal deixis' and $/ \mathrm{ks}^{5} /$ 'deictic suffix' in fast utterance. 
Boersma, Paul \& David Weenink. 2020. Praat: Doing phonetics by computer (version 6.0.18). http://www.praat.org/ (accessed 6 February 2020).

Butcher, Andrew. 1990. "Place of articulation" in Australian languages. In Roland Seidl (ed.), $3 r d$ Australian International Conference on Speech Science and Technology, Melbourne, 420-425.

Cao, Jianfen \& Ian Maddieson. 1992. An exploration of phonation types in Wu dialects of Chinese. Journal of Phonetics 20(1), 77-92.

Chao, Yuen-Ren. 1928. Xiandai Wuyu de Yanjiu [Studies of the modern Wu dialects]. Beijing: Tsinghua Xuexiao Yanjiuyuan.

Chao, Yuen-Ren. 1930. ə sistim əv "toun-letəz" [A system of 'tone-letters']. Le Maître Phonétique 8(45) no. 30, 24-27. [Reprinted in 1980 in Fangyan [Dialects] 2, 81-83.]

Chao, Yuen-Ren. 1967. Contrastive aspects of the Wu dialects. Language 43(1), 92-101.

Chen, Yiya. 2011. How does phonology guide phonetics in segment-fo interaction? Journal of Phonetics 39(4), 612-625.

Chen, Yiya. 2012. Tonal variation. In Abigail Cohn, Cecile Fougeron \& Marie Huffman (eds.), Oxford handbook of laboratory phonology, 103-114. New York: Oxford University Press.

Chen, Yiya \& Carlos Gussenhoven. 2015. Shanghai Chinese. Journal of the International Phonetic Association 45(3), 321-337.

Chitoran, Ioana. 2002. A perception-production study of Romanian diphthongs and glide-vowel sequences. Journal of the International Phonetic Association 32(2), 203-222.

Cole, Ronald A. \& William E. Cooper. 1975. Perception of voicing in English affricates and fricatives. The Journal of the Acoustical Society of America 58(6), 1280-1287.

Connell, Bruce. 2007. Mambila fricative vowels and Bantu spirantisation. Africana Linguistica 13(1), $7-31$.

Dart, Sarah N. 1991. Articulatory and acoustic properties of apical and laminal articulations. UCLA Working Papers in Phonetics 79, 1-155.

Duanmu, San. 2000. The phonology of Standard Mandarin. New York: Oxford University Press.

Erickson, Blaine. 2001. On the origins of labialized consonants in Lao. In Karen L. Adams \& Thomas J. Hudak (eds.), Papers from the 6th Annual Meeting of the Southeast Asian Linguistics Society, Tempe, Arizona State University, 135-148.

Fant, Gunnar. 1960. Acoustic theory of speech production: With calculations based on X-ray studies of Russian articulations. The Hague: Mouton.

Faytak, Matthew \& Susan Lin. 2015. Articulatory variability and fricative noise in apical vowels. In The Scottish Consortium for ICPhS 2015 (ed.), 18th International Congress of Phonetic Sciences (ICPhS XVIII), Glasgow, University of Glasgow, https://www.internationalphoneticassociation.org/ icphs-proceedings/ICPhS2015/Papers/ICPHS0516.pdf.

Faytak, Matthew \& John Merrill. 2015. Bantu spirantization is a reflex of vowel spirantization. Presented at Sound Change in Interacting Human Systems: 3rd Biennial Workshop on Sound Change, Berkeley, University of California, http://linguistics.berkeley.edu/SCIHS/abstracts/5_ FridayAfternoon/Faytak_Merrill.pdf.

Gao, Jiayin. 2015. Interdependence between tones, segments, and phonation types in Shanghai Chinese: Acoustics, articulation, perception, and evolution. Ph.D. dissertation, Université Sorbonne Nouvelle Paris III.

Hirayama, Hisao. 2010. Ciyindiao xingcheng de shengxue yuanyin - Yi Wujiang fangyan weili [On the phonetic cause of the evolution of the Ci-yin tones: The case of the Wujiang dialects]. Zhongguo fangyan xuebao [Journal of Chinese Dialectology] 2, 17-23.

Ho, Dah-An. 1989. Songqifendiao jiqi xiangguan wenti [The tone-split by aspiration and other related problems]. Lishi yuyan yanjiusuo jikan [Bulletin of Institute of History and Philology] 60(4), 765-778.

Howie, John M. 1976. Acoustical studies of Mandarin vowels and tones. Cambridge: Cambridge University Press.

Hu, Fang. 2007. Lun Ningbo fangyan he Suzhou fangyan qiangaoyuanyin de qubietezheng - Jiantan gaoyuanyin jixu gaohua xianxiang [On the distinctive features for the high front vowels in Ningbo and Suzhou Wu dialects with reference to sound changes of high vowels]. Zhongguo yuwen [Studies of the Chinese Language] 5, 455-465. 
Hu, Fang \& Feng Ling. 2019. Fricative vowels as an intermediate stage of vowel apicalization. Language and Linguistics 20(1), 1-14.

Karlgren, Bernhard. 1915. Études sur la phonologie Chinoise I [Studies in Chinese phonology I]. Leyde: Brill \& Stockholm: Norstedt.

Ladefoged, Peter \& Ian Maddieson.1996. The sounds of the world's languages. Oxford: Blackwell.

Lee, Wai-Sum \& Eric Zee. 2003. Standard Chinese (Beijing). Journal of the International Phonetic Association 33, 109-112.

Lee-Kim, Sang-Im. 2014. Revisiting Mandarin 'apical vowels': An articulatory and acoustic study. Journal of the International Phonetic Association 44, 261-282.

Ling, Feng. 2007. The articulatory and acoustic study of fricative vowels in Suzhou Chinese. In Jürgen Trouvain \& William J. Barry (eds.), 16th International Congress of Phonetic Sciences (ICPhS XVI), Saarbrücken, Saarland University, 573-576.

Ling, Feng. 2011. Suzhouhua [i] yuanyin de yuyinxue fenxi [A phonetic study of vowel [i] in the Suzhou Wu dialect]. In Centre for Chinese Linguistics Peking University (ed.), Yuyanxue luncong [Essays on linguistics], vol. 43, 177-193. Beijing: Shangwu Yinshuguan.

Maddieson, Ian \& Karen Emmorey. 1985. Relationship between semivowels and vowels: Cross-linguistic investigations of acoustic difference and coarticulation. Phonetica 42(4), 163-174.

Qian, Nairong. 1992. Dangdai Wuyu Yanjiu [Studies of the contemporary Wu dialects]. Shanghai: Shanghai Jiaoyu Chubanshe.

Ren, Nianqi. 1992. Phonation types and stop consonant distinctions: Shanghai Chinese. Ph.D. dissertation, University of Connecticut.

Sagart, Laurent. 1981. Aspiration-conditioned tone-lowering in Chinese dialects. Presented at 14th International Conference on Sino-Tibetan Languages and Linguistics, Gainesville, University of Florida, https://www.academia.edu/38233622/Aspiration-conditioned_tone_lowering_in_Chinese_ dialects.

Shen, Zhongwei. 1994. The tones in Wujiang dialect. Journal of Chinese Linguistics 22(2), 279-315.

Shen, Zhongwei. 2006. Syllabic nasals in Chinese dialects. Bulletin of Chinese Linguistics 1(1), 77-104. Leiden: Brill.

Shen, Zhongwei, Charles Wooters \& William S.-Y. Wang. 1987. Closure duration in the classification of stops: A statistical analysis. In Brian D. Joseph \& Arnold M. Zwicky (eds.), Ohio State University Working Papers in Linguistics 35, 197-209.

Shi, Feng. 1992. Wujiang fangyan shengdiaogeju de fenxi [The analysis of the tonal space in the Wujiang dialects]. Fangyan [Dialects] 3, 189-194.

Shi, Feng. 1998. Songqi shengmu duiyu shengdiao de yingxiang [The influence of aspiration on tones]. Journal of Chinese Linguistics 26(1), 126-145.

Shi, Menghui, Yiya Chen \& Maarten Mous. 2016. Raising or lowering: The effect of aspiration-induced $f 0$ perturbation in Lili Wu. In Department of Chinese Literature and Language of Fudan University (ed.), 9th International Conference on Wu Dialects, Suzhou, Suzhou University of Science and Technology, 33-36.

Shi, Rujie. 1998. Hanyu fangyan zhong gaoyuanyin de qiangmoca qingxiang [The friction of the high vowel in Chinese dialects]. Yuyan yanjiu [Linguistic Studies] 1, 100-109.

Stevens, Kenneth N. 1989. On the quantal nature of speech. Journal of Phonetics 17(1), 3-45.

Stevens, Kenneth N. \& Sheila E. Blumstein. 1975. Quantal aspects of consonant production and perception: A study of retroflex stop consonants. Journal of Phonetics 3(4), 215-233.

Vaissière, Jacqueline. 2011. On the acoustic and perceptual characterization of reference vowels in a crosslanguage perspective. In Wai-Sum Lee \& Eric Zee (eds.), 17th International Congress of Phonetic Sciences (ICPhS XVII), Hong Kong, City University of Hong Kong, 52-59.

Wang, Li. 1985. Hanyu Yuyinshi [The history of Chinese philology]. Beijing: Zhongguo Shehui Kexue Chubanshe.

Wang, Ping. 1987. Suzhou yinxi zaifenxi [A reanalysis of phonology in the Suzhou dialect]. Yuyan yanjiu [Linguistic Studies] 1, 41-48.

Wang, Ping. 2008. Wujiang fangyan shengdiao zaitaolun [Tones in the Wujiang dialect: A revisit]. Zhongguo yuwen [Studies of the Chinese Language] 5, 455-461. 
Wang, Ping. 2010. Wujiangshi Fangyanzhi [A description of the Wujiang dialects]. Shanghai: Shanghai Shehui Kexue Chubanshe.

Wiese, Richard. 1997. Underspecification and the description of Chinese vowels. In Jialing Wang \& Norval Smith (eds.), Studies in Chinese phonology, 219-249. Berlin \& New York: Mouton de Gruyter.

Wurm, Stephan A., Rong Li, Theo Baumann \& Mei W. Lee (eds.). 1987. Language atlas of China. Hong Kong: Longman.

Xu, Yanhong. 2013. Wujiang fangyan shengdiao shiyan yanjiu [An experimental study in Wujiang citation tones]. MA thesis, Shanghai University.

$\mathrm{Xu}$, Yue. 2006. Jiangshan fangyan de Qiliufendiao [The tone-split by aspiration of the Jiashan dialect]. Yuyan yanjiu [Linguistic Studies] 3, 77-80.

$\mathrm{Xu}$, Zhen. 2009. Wujiang fangyan shengdiao yanjiu [A reinvestigation of tones in the Wujiang dialects]. MA thesis, Shanghai Normal University.

Ye, Xiangling. 1983. Wujiang fangyan shengdiao zaidiaocha [A revisit to tones in the Wujiang dialects]. Fangyan [Dialects] 1, 32-35.

Zhang, Gonggui \& Danqing Liu. 1983. Wujiang fangyan shengdiao chubu diaocha [A preliminary investigation of tones in the Wujiang dialects]. Nanjing Shida xuebao (Shehui kexue ban) [Journal of Nanjing Normal University (Social Science Edition)] 3, 37-40.

Zhao, Rixin. 2007. Hanyu fangyan zhong de [i] > [1] [Sound change [i] > [1] in Chinese dialects]. Zhongguo yuwen [Studies of the Chinese Language] 1, 46-54.

Zhu, Xiaonong. 2004a. Qinmi yu gaodiao: Dui xiaochengdiao, nvguoyin, meimei deng yuyan xianxiang de shengwuxue jieshi [Intimacy and high pitch: A biological explanation for the use of high pitch in diminutives, 'female Mandarin', 'Taiwan sisters', etc.]. Dangdai yuyanxue [Contemporary Linguistics] 3, 193-222.

Zhu, Xiaonong. 2004b. Hanyu yuanyin de Gaodingchuwei [Sound changes of high vowels in Chinese dialects]. Zhongguo yuwen [Studies of the Chinese Language] 5, 440-451.

Zhu, Xiaonong \& Yue Xu. 2009. Chihua: Tansuo Wujiang Ciqingfendiao de yuanyin [Slack voice as the cause of tone split in Wujiang: A phonetic investigation into the pitch contour of the syllables with a voiceless aspirated onset in the Wujiang (Songling) Wu dialect]. Zhongguo yuwen [Studies of the Chinese Language] 4, 324-332. 